\title{
Surface Expression, Polarization, and Functional Significance of CD73 in Human Intestinal Epithelia
}

\author{
Gregg R. Strohmeier, ${ }^{\star}$ Wayne I. Lencer, ${ }^{\S}$ Thomas W. Patapoff, ${ }^{\natural}$ Linda F. Thompson, Susan L. Carlson, ${ }^{\star \S}$ Signa J. Moe, ${ }^{\ddagger \S}$ \\ Denice K. Carnes, ${ }^{\star \S}$ Randall J. Mrsny,, and James L. Madara ${ }^{\star \S}$ \\ Division of Gastrointestinal Pathology, *Department of Pathology, Brigham and Women's Hospital, Harvard Medical School; \\ ${ }^{\ddagger}$ Department of Pediatrics, Children’s Hospital Medical Center and Harvard Medical School and the ${ }^{\S}$ Harvard Digestive Diseases Center, \\ Boston, Massachusetts 02115; "Oklahoma Medical Research Institute, Oklahoma City, Oklahoma 73104; and "Genentech Inc., South \\ San Francisco, California 94080
}

\begin{abstract}
During active intestinal inflammation polymorphonuclear leukocytes (PMN) transmigrate into the lumen and release 5'-AMP (J. Clin. Invest. 1993. 91:2320-2325). 5'-AMP is converted to adenosine by the apical epithelial surface with subsequent activation of electrogenic $\mathrm{Cl}^{-}$secretion (the basis of secretory diarrhea) via apical $\mathrm{A}_{2 \mathrm{~b}}$ adenosine receptors (J. Biol. Chem. 1995. 270:2387-2394). Using a polarized human intestinal epithelial monolayer (T84), we now characterize the basis of the observed conversion of 5'-AMP to adenosine required for this paracrine signaling pathway. An inhibitor of the ecto-5'-nucleotidase CD73, $\alpha, \beta$-methylene ADP (AOPCP), inhibited epithelial $\mathrm{Cl}^{-}$secretory responses to 5'-AMP, but not to authentic adenosine. Confocal immunofluorescent microscopy revealed CD73 to be surface expressed on both model and natural human intestinal epithelia. Expression was about sixfold greater on the apical cell surface as assessed biochemically by selective cell surface biotinylation, and morphologically by immunofluorescence. Treatment with phosphotidylinositol specific-phospholipase C (PI-PLC) released 95\% of apical CD73, indicating that the intestinal CD73 possesses a glycosylphosphatidylinositol (GPI) anchor. Neither adenosine nor 5'-AMP stimulation induced intact T84 cells to shed surface CD73. The bulk of apical CD73 $(\sim 60 \%)$ was released from the cell surface by treatment with $1 \%$ Triton X-100 (TX-100) at $4^{\circ} \mathrm{C}$, but such release was not affected by pretreatment with ligand or by prior, antibody-mediated cross-linking of CD73. Subsequent analyses showed that the subpool of CD73 released by $\mathrm{TX}-100$ at $4^{\circ} \mathrm{C}$ was not truly solubilized, but rather represented TX-100-induced release of CD73-containing membrane fragments. These membrane fragments displayed light density on sucrose gradients characteristic of detergent insoluble glycosphingolipid-rich membrane domains (DIGs)/ caveolae, were solubilized by $n$-octyl glucoside (NOG, $1 \%$ ) at $4^{\circ} \mathrm{C}$, and contained caveolin. These data indicate that human intestinal epithelia express CD73, which is apically po-
\end{abstract}

Address correspondence to Dr. Gregg R. Strohmeier, Department of Pathology, Brigham and Women's Hospital, 20 Shattuck Street, Thorn 1419, Boston, MA 02115. Phone: 617-732-6530; FAX: 617-7326796; E-mail: GRStromei@BICS.BWH.Harvard.edu

Received for publication 24 October 1996 and accepted in revised form 10 March 1997.

J. Clin. Invest.

(C) The American Society for Clinical Investigation, Inc.

0021-9738/97/06/2588/14 \$2.00

Volume 99, Number 11, June 1997, 2588-2601 larized and targeted to microdomains with DIGs/caveolae characteristics. CD73 likely participates in translating paracrine, PMN-derived 5'-AMP signals to the authentic effector adenosine. These studies define CD73 as central to PMN-mediated intestinal $\mathrm{Cl}^{-}$secretion, the major directacting mechanism by which PMN induce intestinal epithelial $\mathrm{Cl}^{-}$secretion. (J. Clin. Invest. 1997. 99:2588-2601.) Key words: caveolae $\bullet$ chloride secretion $\bullet$ ecto-5' -nucleotidase • mucosal inflammation $\cdot$ neutrophil-epithelial interactions

\section{Introduction}

PMN and eosinophils migrate across the epithelial lining of the intestinal crypt and into the intestinal lumen during the active phase of many intestinal diseases (1). Upon activation, both PMN and eosinophils release 5'-AMP that, when presented to the apical surface of crypt-like intestinal epithelial cells, is converted to adenosine (2). Adenosine then activates electrogenic chloride secretion, the basis of secretory diarrhea. Thus, PMNderived 5'-AMP serves as a paracrine signal to intestinal epithelial cells, which possess both the means of converting this precursor to adenosine and then receptors to recognize the adenosine product. While we have characterized the apical intestinal epithelial adenosine receptor as the $\mathrm{A}_{2 \mathrm{~b}}$-adenosine receptor (3), the biological basis by which the epithelial surface converts 5'-AMP to adenosine remains undefined.

We show here that intestinal epithelial cells express on their surface the ecto-5' -nucleotidase CD73 in apically polarized fashion. Intestinal epithelial cells, like other cell types, express CD73 in a GPI linkage. Further, CD73 appears to be largely sequestered in a microdomain of T84 cell membranes that display biophysical characteristics of detergent insoluble glycolipid rafts (DIGs) ${ }^{1}(4)$. DIGs are putatively involved in clustering proteins for efficient transmembrane signal transduction (5). We also find that inhibition of CD73 with $\alpha, \beta$-methylene ADP (AOPCP) (6-9) renders T84 cells less sensitive to either 5' AMP or PMN-conditioned supernatants, but not adenosine (apical 5' AMP elicited short circuit current, Isc, $\mathrm{ED}_{50}$ is shifted 30 -fold to the right). These data indicate that CD73 may play a critical role in the cascade of signaling events by

1. Abbreviations used in this paper: Ado, adenosine; AdoR, adenosine receptor; AOPCP, $\alpha, \beta$-methylene adenosine diphosphate; CD73, ecto-5'-ectonucleotidase; DAF, decay accelerating factor; DIGs, detergent-insoluble glycolipid-enriched complexes; ECL, enhanced chemiluminescence; GPI, glycosylphosphatidyl inositol; NDS, neutrophil-derived secretagogue; NECA, N-ethylcarboxamidoadenosine; NOG, $n$-octyl glucoside; PI-PLC, phosphotidylinositol specificphospholipase $\mathrm{C}$; RT, room temperature; $5^{\prime}$-NT, ecto-5' -nucleotidase. 
which PMN (or eosinophils) directly stimulate $\mathrm{Cl}^{-}$secretion in intestinal epithelia.

\section{Methods}

Lysis buffer. $20 \mathrm{mM}$ Tris- $\mathrm{HCl} \mathrm{pH} 8.0,150 \mathrm{mM} \mathrm{NaCl}, 1 \mathrm{mM}$ PMSF, $10 \mu \mathrm{M}$ antipain, $20 \mu \mathrm{g} / \mathrm{ml}$ chymostatin, $1 \mathrm{mM}$ leupeptin, $1 \mu \mathrm{g} / \mathrm{ml}$ pepstatin $\mathrm{A}$, and $12.5 \mu \mathrm{g} / \mathrm{ml}$ trypsin inhibitor.

Cell culture. Approximately 500 individual monolayers were used for these studies. Monolayers of the human intestinal epithelial cell line T84 were grown to confluency on collagen-coated permeable supports (inserts). Inserts rested in wells containing media until steady-state resistance was achieved, as previously described (10). This permits apical and basolateral membranes to be separately interfaced with apical or basolateral buffer, a configuration identical to that previously developed for a microassay (11). Measurements of transepithelial resistance, voltage, and Isc were performed in Hanks' balanced salt solution $\left(\mathrm{HBSS}^{+}\right.$) using standard biophysical techniques as previously described (10-12). All pharmacologic agents and stimuli were added to the monolayers by the addition to the buffer of a $1 / 10$ th final volume of freshly diluted $10 \times$ stock in buffer. Concentrated stocks were made according to manufacturers' instructions.

Confocal fluorescence microscopy. T84 cell monolayers were fixed in $3.7 \%$ paraformaldehyde in $\mathrm{PBS}, \mathrm{pH} 7.4$, at $4^{\circ} \mathrm{C}$ for $20 \mathrm{~min}$, excised as circles from the inserts, and extracted for $3 \mathrm{~min}$ in acetone at $-20^{\circ} \mathrm{C}$. Insert monolayers were rinsed twice with gel PBS $(0.2 \%$ gelatin, $150 \mathrm{mM} \mathrm{NaCl}, 10 \mathrm{mM} \mathrm{NaH}_{2} \mathrm{PO}_{4}$ ) then incubated with anti-CD73 monoclonal antibody $7 \mathrm{G} 2$ diluted to $\approx 0.25 \mathrm{mg} / \mathrm{ml}$ in gel $\mathrm{PBS}$ for $1 \mathrm{~h}$ at room temperature (RT) in a moist environment. After four 3-min washes in gel PBS, monolayers were incubated with FITC-conjugated goat anti-mouse IgG (Organon Teknika-Cappel, Durham, NC) diluted 1:100 in gel PBS for $1 \mathrm{~h}$ at RT in a moist and dark environment. Inserts were then rinsed four times for $3 \mathrm{~min}$ in gel PBS, cut into rectangles, placed on glass slides, and mounted with $p$-phenylene-diamine/ glycerol/PBS mounting medium, and examined on a Zeiss Axiophot equipped with a laser scanning confocal system (MCR-600; Biorad Laboratories, Hercules, CA). Stains performed in the absence of the primary or secondary antibodies constituted negative controls.

For localization of CD73 along the axis of the normal human intestine, human mucosa from various levels were obtained from surgically resected specimens (approved by the Human Subjects Committee), prepared using standard histological techniques, and stained as described above.

Selective cell surface biotinylation. T84 monolayers exhibit high resistance to passive flow of solutes and thus can be selectively surface labeled. For this purpose monolayers were grown on $5-\mathrm{cm}^{2}$ inserts and transepithelial resistance verified. They were then washed in $\mathrm{HBSS}^{+}$at $4^{\circ} \mathrm{C}$, and subsequently sulfo-NHS-biotin was added either apically, basolaterally, or to both surfaces (total surface) at 0.2 $\mu \mathrm{g} / \mathrm{ml}$ as previously described (13-16). The reservoir contralateral to that exposed to sulfo-NHS-biotin was exposed to the same concentration of sulfo-NHS-acetate as a blocking reagent. Monolayers were then labeled by incubation for $20 \mathrm{~min}$ at $4^{\circ} \mathrm{C}$ with gentle agitation, and labeling was stopped by washing with quench buffer $(50 \mathrm{mM}$ sodium acetate/HBSS $\left.{ }^{+}\right) 3 \times, 5$ min each wash. Monolayers were scraped off their filter support in lysis buffer lacking detergent, pelleted (10 min at 1,000 rpm), and the pellet was resuspended in lysis buffer containing $1 \% n$-octylglucoside (NOG) as detergent and tumbled for 30 min, at $4{ }^{\circ} \mathrm{C}$. Cell extracts were clarified by microcentrifugation and precleared for at least $2 \mathrm{~h}$ with nonspecific mouse IgG1-sepharose beads. Mouse $\mathrm{IgG}_{1}$-sepharose beads were settled by micro-centrifugation and the resultant supernatant was removed and placed in a fresh eppendorf tube. Precleared cell extract supernatant was incubated overnight with sepharose beads coupled to either anti-decay accelerating factor (DAF, CD55) or anti-CD73 mAb. After thorough washing, protein was recovered from the sepharose beads using $2 \times$ sample buffer $(60 \mathrm{mM}$ Tris, $\mathrm{pH}$ 6.8, 2\% SDS, $0.1 \%$ glycerol, and
$0.001 \%$ bromophenol blue dye) lacking reducing agent to prevent release of the coupled antibody from the beads. Recovered protein was run on $10 \%$ polyacrylamide gels (SDS-PAGE [17]), and transferred to $0.2 \mu \mathrm{m}$ nitrocellulose for $2 \mathrm{~h}$ at $100 \mathrm{~V}$ at $4^{\circ} \mathrm{C}(18)$. Nitrocellulose sheets were blocked overnight at $4{ }^{\circ} \mathrm{C}$ with rocking (in $0.5 \%$ gelatin, $0.1 \%$ Tween, $0.05 \%$ Thimerasol in PBS), and incubated for $1 \mathrm{~h}$ with rocking at RT with peroxidase-conjugated streptavidin diluted 1:10,000 from a $2-\mathrm{mg} / \mathrm{ml}$ stock in DMSO. Biotinylated, immunoprecipitated protein was visualized by enhanced chemiluminescence (ECL) according to manufacturers instructions (Amersham) and exposed to Kodak x-ray film.

For experiments examining the release of CD73, monolayers were biotinylated, quenched as above, then washed with $37^{\circ} \mathrm{C}$ HBSS + and incubated for $10 \mathrm{~min}$ at $37^{\circ} \mathrm{C}$. After recording their Isc and resistance, stimulus was applied (either buffer, or $10 \mu \mathrm{M}$ apical +100 $\mu \mathrm{M}$ basolateral adenosine, or $1 \mathrm{U} / \mathrm{ml}$ final of phosphotidylinositol specific-phospholipase C (PI-PLC) to both reservoirs) by addition of a $10 \times$ stock solution. Cells were incubated $45-60 \mathrm{~min}$, with one Isc reading taken at $5 \mathrm{~min}$ to confirm stimulation (Isc responses were $\sim 10$-fold baseline, the same response as that observed in cells that were mock biotinylated). Cells were washed in $\mathrm{HBSS}^{+}, 4^{\circ} \mathrm{C}$, scraped, solubilized, and CD73 was immunoprecipitated as above.

Detergent solubility. Cells were biotinylated and quenched as above, then the monolayers were cut out and tumbled at $4^{\circ} \mathrm{C}$ in the lysis buffer containing $1 \% \mathrm{TX}-100$ for $30 \mathrm{~min}$. The solution was removed and saved on ice, and monolayers were washed with the same buffer $3 \times, 5 \mathrm{~min}$, at $4^{\circ} \mathrm{C}$. Subsequently $1 \%$ NOG was added to TX100 -lysis buffer and this was used to solubilize any proteins not recovered by the TX-100 extraction and washes (adapted from Lisanti [19]). Subsequent to immunoprecipitation, samples were analyzed by SDS-PAGE and avidin-HRP blot and bands quantified by densitometry using NIH Image.

Sucrose gradients. To determine whether CD73 might be found in a low density fraction, one $45-\mathrm{cm}^{2}$ plate of confluent T84 cells was washed in cold HBSS +, then scraped with a rubber policeman into cold lysis buffer lacking detergent. The cells were pelleted for $5 \mathrm{~min}$ at $1,200 \mathrm{rpm}$, and solubilized in cold TX-100 lysis buffer, $2 \mathrm{ml}$ per $45 \mathrm{~cm}^{2}$ plate, and homogenized with six strokes in a dounce homogenizer using a loose-fitting pestle. In some experiments, this extract was centrifuged $10 \mathrm{~min}$ at 2,500 $\mathrm{rpm}, 4^{\circ} \mathrm{C}$ and the supernatant was transferred to a fresh tube and mixed $1: 1$ with $60 \%$ sucrose $(2.255 \mathrm{M})$. In other experiments, the extract was not cleared after douncing but directly mixed with $60 \%$ sucrose. In both methods, the $4 \mathrm{ml}$ was transferred to a centrifuge tube and a linear 5 to $30 \%$ sucrose gradient in TBS minus detergent was layered over the lysate and centrifuged for $19 \mathrm{~h}$ at $39,000 \mathrm{rpm}$ at $4^{\circ} \mathrm{C}$ in an SW41-Ti rotor (Beckman Instruments, Inc., Fullerton, CA). Subsequently, $0.5-\mathrm{ml}$ fractions were collected from the top of the gradient, and the percent sucrose of each fraction was measured by refractometry. Turbidity of fractions was determined at $600 \mathrm{~nm} \mathrm{OD}$, and protein concentration was analyzed using the Bradford assay (Biorad). $60 \mu \mathrm{l}$ of each sample was then combined with 20 $\mu \mathrm{l} 4 \times$ sample buffer, SDS-PAGE performed as above (the blocking buffer additionally contained $0.5 \%$ Blotto) and the blots incubated with monoclonal antibody (anti-CD73 1E9, or anti-caveolin from $\mathrm{Hu}-$ man Transduction Laboratories, Lexington, KY) for $1 \mathrm{~h}$ at RT, washed $3 \times$ in $0.1 \%$ Tween-PBS (TPBS), $1 \times$ in blocking buffer, then incubated with goat anti-mouse IgG coupled to horseradish peroxidase for $1 \mathrm{~h}$ at RT with rocking, washed $4 \times$ in TPBS, $2 \times$ in PBS, and visualized by ECL as above. In a subset of experiments examining polarity, one $45-\mathrm{cm}^{2}$ plate was biotinylated as above, floated in a sucrose gradient, each fraction immunoprecipitated, and SDS-PAGE performed on the fractions.

HPLC analysis of CD73 activity. T84 cells were washed, then incubated apically for $30 \mathrm{~s}$, or 2, 5, 10, or $30 \mathrm{~min}$ with $10 \mu \mathrm{M} 5^{\prime}$-AMP, and the reservoir supernatant collected and placed immediately on ice. These samples were rapidly passed through a $0.2-\mu \mathrm{m}$ acrodisc (Gelman Sciences, Inc., Ann Arbor, MI), then passed through a 30,000 mol wt cut-off centricon filter (Amicon, Inc., Beverly, MA) by 
centrifugation at $6,000 \mathrm{rpm}$ for $15 \mathrm{~min}$ at $4^{\circ} \mathrm{C}$, and frozen at $-80^{\circ} \mathrm{C}$. Later, the $5^{\prime}$-AMP/adenosine ratio of the samples were determined by HPLC analysis. A subset of T84 monolayers were pretreated with NDS (neutrophil-derived secretagogue, the partially purified neutrophil bioactivity for which $5^{\prime}$-AMP represents the active product) produced as described (20): in brief, PMN at $10^{7} / \mathrm{ml}$ in $\mathrm{HBSS}^{+}$were incubated for at least $1 \mathrm{~h}$ with $0.1 \mu \mathrm{g} / \mathrm{ml}$ PMA with tumbling at $37^{\circ} \mathrm{C}$, then pelleted and the supernatant was frozen until used as NDS; in some cases, this NDS was passed through a $10,000 \mathrm{~mol}$ wt centricon cut-off filter and designated filtered NDS. The monolayers exposed to NDS for $30 \mathrm{~min}$ were then washed and subsequently exposed to $5^{\prime}$-AMP and the reservoirs harvested as above and analyzed for their 5 '-AMP/adenosine ratios. Lastly, supernatants of cells exposed to buffer, NDS, or 5'-AMP for 30 min were directly analyzed without filtering for CD73 activity by examining 5'-AMP conversion to adenosine using HPLC. The reversed phase HPLC method consisted of a gradient from 2 to $70 \%$ acetonitrile/trifluoroacetic acid in 5 min using a 10-cm ODS Hypersil column (Hewlett Packard, Co., Palo Alto, $\mathrm{CA}$ ). The advantages of such a system is that both the adenosine and 5 '-AMP can be determined in a single method.

Reagents. All tissue culture supplies were obtained from Gibco Laboratories (St. Lawrence, MA). Anti-CD73 antibodies 7G2 and 1E9 produced as described (21). Anti-DAF antibodies were the kind gift of Dr. Greg Stahl (Department of Anesthesia, Brigham and Women's Hospital). All other reagents were obtained from Sigma Chemical Co. (St. Louis, MO).

\section{Results}

Electrogenic $\mathrm{Cl}^{-}$secretion (Isc) stimulation by PMN. Transmigration of PMN across intestinal epithelia results in exposure of the epithelial apical membrane to the neutrophil-derived secretagogue, 5'-AMP. As previously shown, such interactions can be modeled and synchronized by addition of PMN to the apical compartment in the presence of the activating chemotactic agent fMLP $\left(10^{-8} \mathrm{M}\right)$. As a result, such activated PMN stimulate a maximal Isc response of $22 \pm 3 \mu \mathrm{A} / \mathrm{cm}^{2}$ (all data for Fig. 1 is mean \pm SE, $n=5$ ) at 5 min (Fig. 1). Pretreatment of the T84 cells with the competitive inhibitor of the ecto-5'-nucleotidase, $\alpha, \beta$-methylene ADP (AOPCP [6-9]) reduces the maximal Isc response by $40 \%$ (to $13 \pm 3.5 \mu \mathrm{A} / \mathrm{cm}^{2}$ ). Likewise, the adenosine receptor (AdoR) antagonist 8-phenyltheophylline (8PT, $1 \mu \mathrm{M}$ [9]), abrogates the Isc response to neutrophil products (peak response at $5 \mathrm{~min}$ of $5.7 \pm 1 \mu \mathrm{A} / \mathrm{cm}^{2}$, from a baseline of $\left.1.4 \pm 0.1 \mu \mathrm{A} / \mathrm{cm}^{2}\right)$. Addition of adenosine deaminase (ADA, $1 \mathrm{U} / \mathrm{ml}$ ), which catalyzes the conversion of adenosine to inosine, completely inhibits the neutrophil-elicited Isc response (Fig. 1, 1.6 $\pm 0.2 \mu \mathrm{A} / \mathrm{cm}^{2}$ at $5 \mathrm{~min}$ ). As neutrophil transmigration proceeds throughout the 2-h time course, the Isc returns to baseline (the lesser apparent Isc response observed at $60 \mathrm{~min}$ is absent in responses elicited by purified 5'AMP (not shown), suggesting this small response is due to the physical effects of neutrophil transmigration). These data verify that activated neutrophils elicit electrogenic $\mathrm{Cl}^{-}$secretion from intestinal epithelia via an adenosine-mediated pathway $(2,20)$ and suggest that the known bioactivity $\left(5^{\prime}\right.$-AMP) responsible for such secretion is converted at the epithelial surface to adenosine perhaps due to surface expression of CD73 (we have previously shown that PMN cannot convert secreted 5'-AMP to adenosine [2]).

AOPCP effect on the adenosine and 5'-AMP dose-response curves. To confirm that treatment of T84 cells with AOPCP affected only the conversion of 5'-AMP to adenosine and not the binding of adenosine to its receptor or its subsequent signal

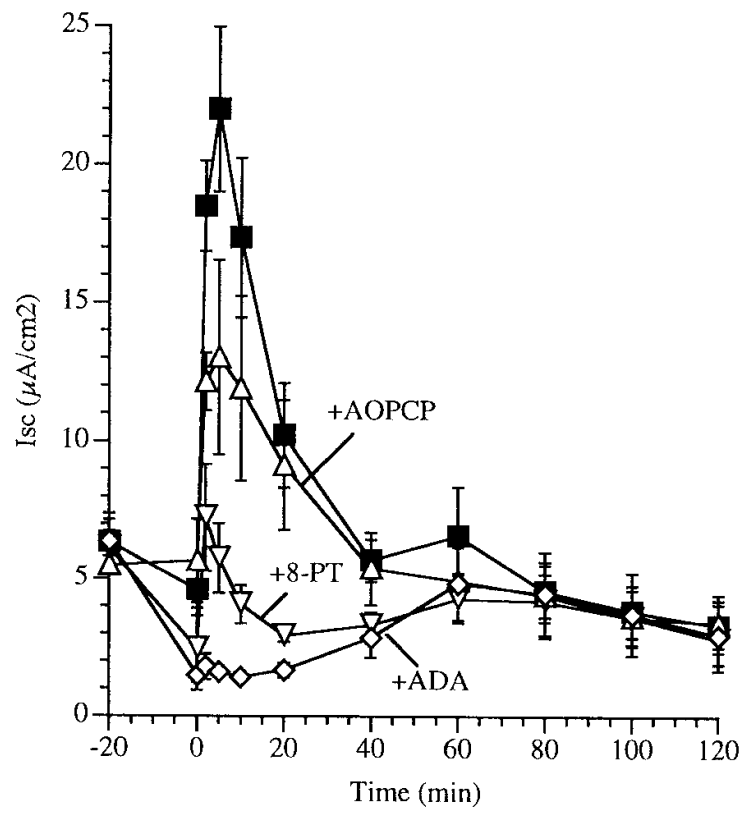

Figure 1. Effect of CD73 inhibition on T84 Isc elicited by PMN. Confluent T84 cells were treated with CD73 inhibitor AOPCP $(1 \mathrm{mM}$, $\triangle)$, AdoR antagonist 8-phenyltheophylline ( $1 \mu \mathrm{M} 8 \mathrm{PT}, \boldsymbol{\nabla})$, or adenosine deaminase (1 U ADA, $\diamond)$. Controls were buffer treated $(\boldsymbol{\square})$. All incubations were initiated at $t=-20 \mathrm{~min}$, the chemotactic peptide fMLP was added to the basolateral reservoir $(1 \mu \mathrm{M})$ at $t=-5$ $\min$, and at $t=0 \min 2 \times 10^{6} \mathrm{PMN}$ were added to the apical reservoir. Isc $\left(\mu \mathrm{A} / \mathrm{cm}^{2}\right)$ responses were recorded and are plotted here versus time. Each point represents the mean of at least four experiments performed in triplicate.

transduction, cells were treated with AOPCP and then stimulated with a range of doses of adenosine or 5'-AMP. As shown in Fig. 2, T84 cells exhibit an Isc dose response to either apical or basolateral adenosine addition, with an $\mathrm{ED}_{50}$ of $0.6 \pm 0.1$ and $4 \pm 0.6 \mu \mathrm{M}$, respectively. This one-log shift in difference between apical and basolateral stimulation was previously shown to be due to basolateral uptake of adenosine, resulting in the requirement for a higher concentration basolaterally to obtain a response (3). When CD73 is inhibited using AOPCP, there is no significant effect upon the adenosine dose curve for either apical or basolateral adenosine stimulation (Fig. $2 \mathrm{~B}$; control: apical adenosine Isc $\mathrm{ED}_{50}=0.6 \pm 0.1 \mu \mathrm{M}$, basolateral $=$ $3.8 \pm 0.6 \mu \mathrm{M}$; treatment with AOPCP: apical adenosine $=$ $0.7 \pm 0.1 \mu \mathrm{M}$, basolateral $=6.3 \pm 1.9 \mu \mathrm{M})$. In contrast, while in monolayers not treated with AOPCP 5'-AMP elicits a doseresponse curve essentially indistinguishable from that induced by adenosine (Fig. $2 A$, apical $\mathrm{ED}_{50}=0.9 \pm 0.3 \mu \mathrm{M}$ and basolateral $=9.7 \pm 3.9 \mu \mathrm{M})$, treatment of T84 cells with AOPCP resulted in an $\sim 30$-fold shift to the right in the apical $5^{\prime}$-AMP dose curve (apical 5'-AMP ED $5_{50}=27 \pm 10 \mu \mathrm{M}$ ) and a 55-fold shift in the basolateral $5^{\prime}$-AMP dose curve $\left(\mathrm{ED}_{50}=520 \pm 200\right.$ $\mu \mathrm{M})$. Thus, when ecto- $5^{\prime}$-nucleotidase activity is inhibited, a much greater concentration of $5^{\prime}$-AMP is required to elicit an Isc response. These data confirm that AOPCP is inhibiting only the conversion of $5^{\prime}$-AMP to adenosine. Thus, specificity of the ecto-nucleotidase inhibitor is confirmed, since the current data supplement our previous findings showing that (a) $5^{\prime}$-AMP is the neutrophil-derived secretagogue (HPLC and mass spectroscopy [2]), (b) that adenosine is the final agonist 


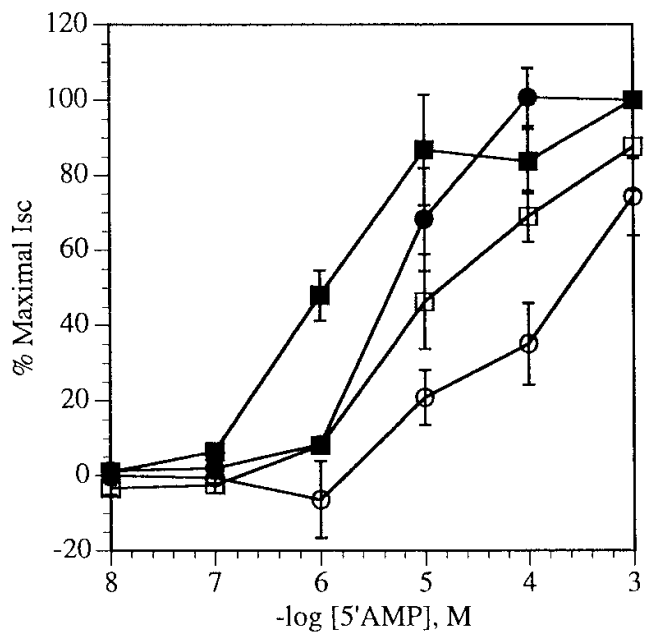

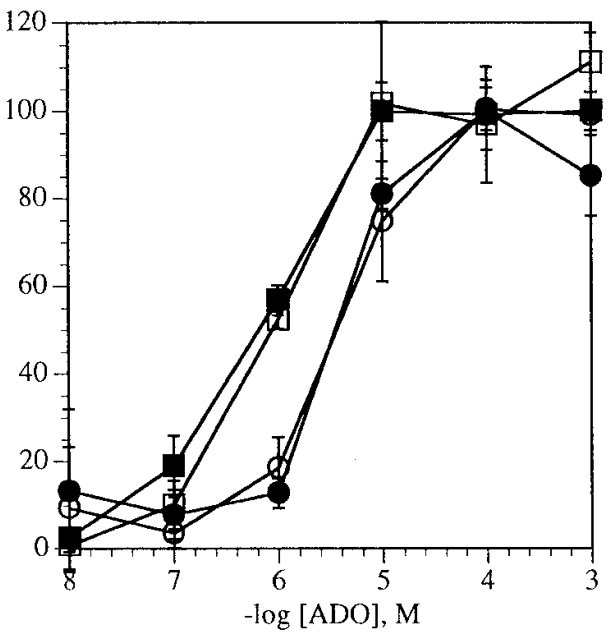

Figure 2. Isc dose response curves for adenosine or $5^{\prime}$-AMP in the presence of CD73 inhibitor. Confluent T84 cells were treated with CD73 inhibitor AOPCP (1 mM, open symbols) both apically and basolaterally for $15 \mathrm{~min}$ before stimulating the cells either apically (squares) or basolaterally (circles) with varying concentrations of adenosine (right) or 5'-AMP (left). Control, untreated, stimulated cells are shown in solid symbols. Data are presented as the percent of the maximal Isc response observed in each experiment for the control condition, and are the mean \pm SEM of at least three experiments performed in triplicate.
(HPLC [2]), (c) that 5'-AMP is not a ligand for the adenosine receptor (9), and $(d)$ that both model and natural intestinal epithelial cells express the $A_{2 b}$ receptor and only the $A_{2 b}$ receptor (Northern blots and PCR based on common adenosine receptor sequences [3]). In addition, these data provide an initial assessment of the polarity of $\mathrm{CD} 73$, since treatment with AOPCP affected the apical as well as the basolateral $5^{\prime}$-AMP stimulation. Likewise, since the time course for apical 5 '-AMP stimulation is no different from the time course of basolateral stimulation (not shown), the presumptive ecto-enzyme $5^{\prime}$-nucleotidase activity must be present on both apical and basolateral membranes in sufficient copy number to yield similar conversion rates.

Conversion of 5'-AMP to adenosine by the epithelial surface. To examine the conversion of $5^{\prime}$-AMP to adenosine, T84 cells were stimulated either apically or basolaterally with the apical dose of 5'-AMP yielding a maximal Isc response, 10 $\mu \mathrm{M}$. The supernatants containing the agonist were collected from the cells at various time points and cooled, then rapidly filtered through 1,000-kD nominal molecular mass cutoff filters to ensure that any potential shedding of the ecto-enzyme would not effect subsequent analyses of 5'-AMP to adenosine conversion. The ratio of $5^{\prime}$-AMP to adenosine was analyzed by HPLC as an indication of the ecto- $5^{\prime}$-nucleotidase activity for apical or basolateral membranes. As shown in Fig. 3, conversion of $5^{\prime}$-AMP to adenosine in the basolateral reservoir (Fig. $3 \mathrm{~B}$ ), while detectable over the 30 -min assay, was extremely limited. In contrast, conversion of $5^{\prime}$-AMP to adenosine in the apical reservoir was rapid, with an estimated crude initial rate of $5.4 \times 10^{-8} \mathrm{M} / \mathrm{cm}$-h. At $2 \mathrm{~min}$, the $5^{\prime}$-AMP/adenosine concentration ratio in the apical reservoir was 4.4 ; by $10 \mathrm{~min}$, this ratio was $\sim 1$; and by $30 \mathrm{~min}$ the concentration of adenosine exceeded that of $5^{\prime}$-AMP.

Because of the suggested presence of a CD73-like bioactivity and differences in apparent conversion rates of $5^{\prime}$-AMP to adenosine at apical and basolateral surfaces, the surface expression and polarity of CD73 was subsequently examined directly by two additional methods, confocal microscopy and by a selective cell surface biotinylation assay.
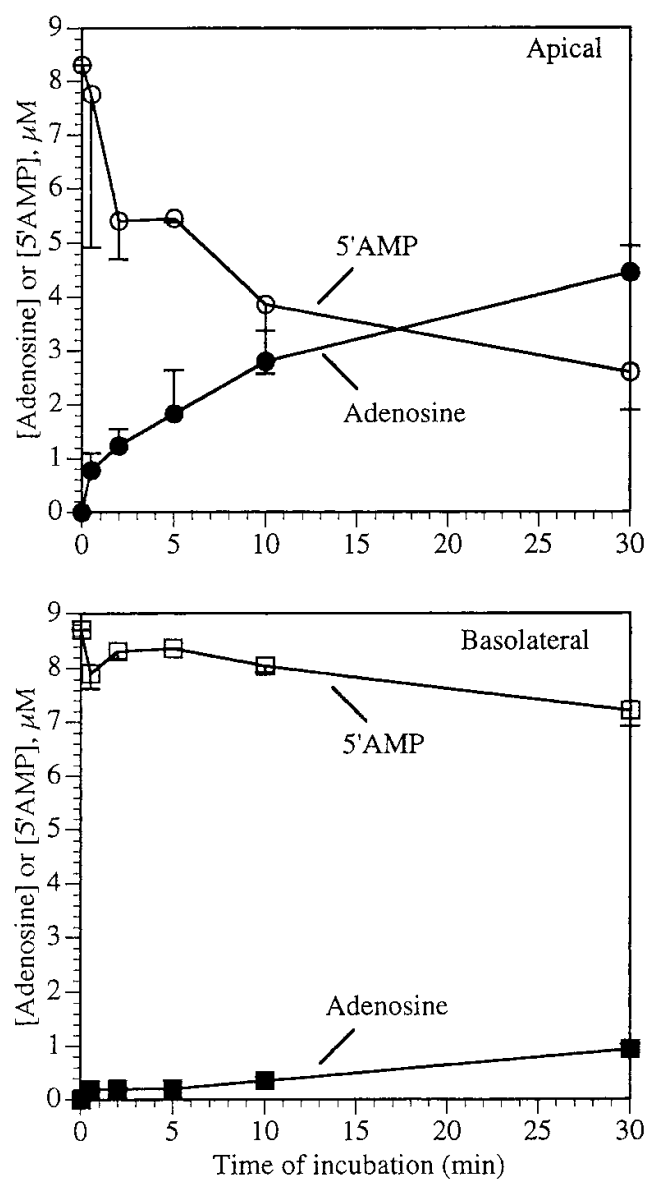

Figure 3. Conversion of 5'-AMP to adenosine by T84 cells. T84 cells were stimulated with $10 \mu \mathrm{M} 5^{\prime}$-AMP apically or basolaterally and the reservoir recovered after $30 \mathrm{~s}$, or 2, 5, 10, or $30 \mathrm{~min}$ and immediately placed on ice, then centrifuged as described in Methods. The solutions were frozen, then later analyzed by HPLC for their adenosine and $5^{\prime}$-AMP concentrations. Data are the average of two experiments. Control cells: apical [5'-AMP] $(\bigcirc)$, and [adenosine] in the same sample (๑); basolateral [5'-AMP], $(\square)$, and [adenosine] in the same sample (ם). 

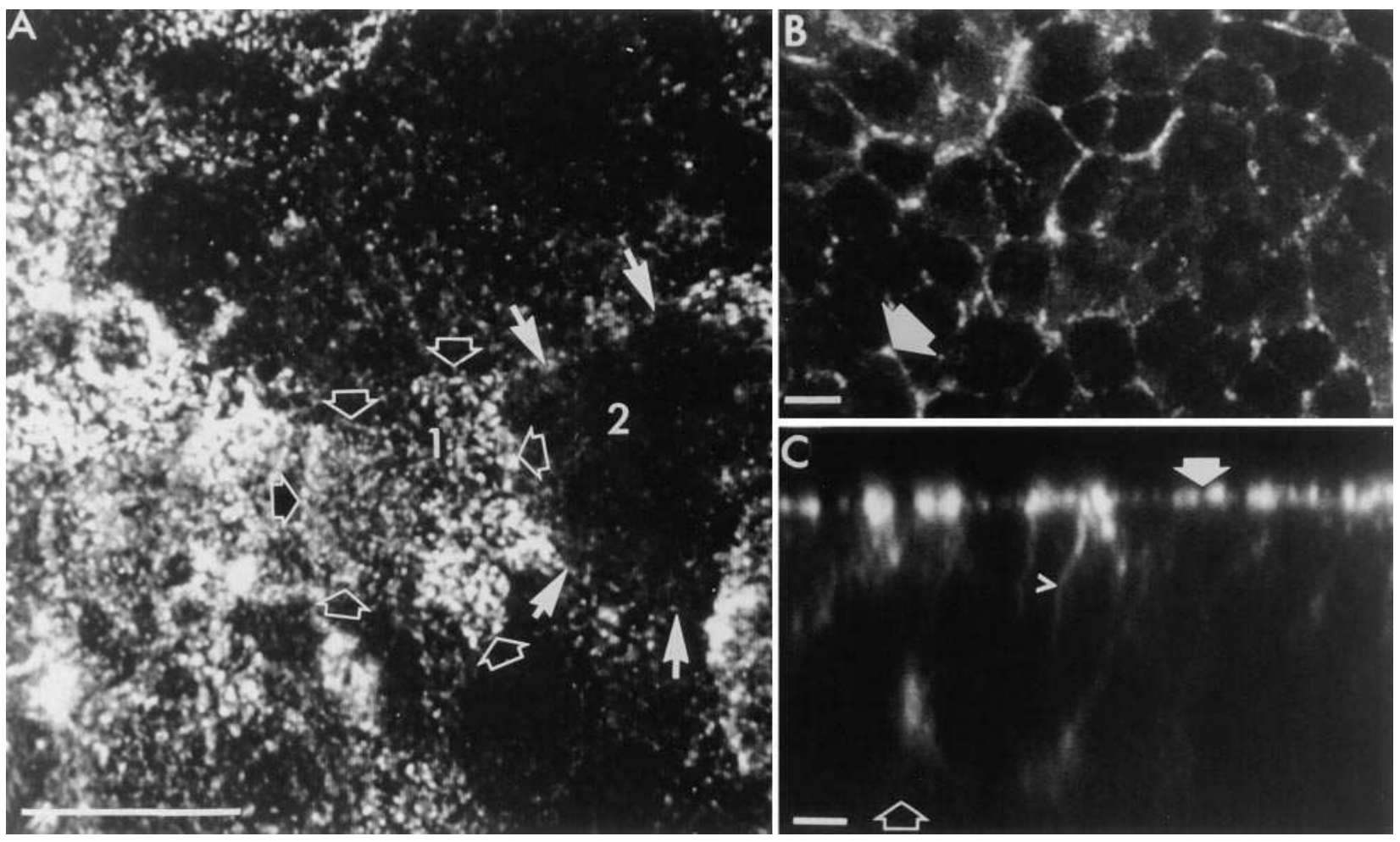

Figure 4. Immunolocalization of CD73 in T84 cells. Confluent T84 cells were examined by confocal microscopy as described in Methods using anti-CD73 monoclonal antibody 1E9. (A) An en face view of the T84 apical membrane (1 indicates a heavily staining cell whose border is indicated by the open arrows, and 2 labels a light staining cell whose border is indicated by closed arrows). ( $B$ ) En face view focusing on the mid axes, demonstrating foci of CD73 staining. The closed arrow indicates a site of multiple cell contact with a higher apparent expression of CD73. (C) $x-z$ axis reconstructions of T84 CD73 staining showing that CD73 is predominantly but not exclusively apically localized. Solid arrow indicates the apical membrane, the open arrow designates the basal membrane, and the arrowhead points to one site of moderate lateral staining.

Confocal immunolocalization of CD73. Surface expression of CD73 on T84 cells was examined by confocal fluorescent microscopy using anti-CD73. As shown in Fig. 4, a specific and strong fluorescent signal was observed at the apical membrane (refer to negative control of Fig. $5 \mathrm{~A}$ ) while basolateral membranes, while not completely negative, stained weakly. En face views of the apical membrane (Fig. $4 A$ and $B$ ) revealed punctate staining patterns with cell to cell variation in staining density. $x-z$ axis reconstructions (Fig. $4 C$ ) confirmed the predominant (but not exclusive) apical staining. We next determined if CD73 was similarly surface expressed in the normal human intestine, particularly in the crypt, which is the major site of PMN transmigration in many intestinal diseases and which corresponds to the cell type that T84 cells are thought to most accurately model. As shown in Fig. 5, $A-D$, proximal human duodenum (proximal small intestine) expressed CD73 polarized to the apical membrane and expressed by the brush border of absorptive cells of the lower third of the villus (Fig. $5 B$ and at higher magnification Fig. $5 C$ ). At this site, the $\mathrm{Cl}^{-}$ secretory cells lining the crypt also stained strongly for apical CD73 (Fig. 5, $B$ and $C$ ). Aside from apical membranes of epithelial cells, staining was noted only on the endothelial cells of the microvasculature. In the ileum (Fig. 6), villus absorptive cells were negative and staining was restricted to the crypt compartment in which apical membrane staining was again present (Fig. 6), although variation in staining density between adjacent crypts was noted. In the ascending colon (proximal large intestine) focal staining of crypt, but not surface, epithelial cells were again present (Fig. 6). Crypt staining was largely confined to the apical membrane although here substantial granular subapical staining (presumably representing a submembranous vesicular compartment) as well as focal lateral membrane staining was observed. In the sigmoid colon (distal large intestine, not shown) surface epithelia were unstained and crypt epithelia were either unstained or, focally, equivocally stained. Analyses of other alimentary tract epithelia (esophagus, gastric antrum, gastric fundus, not shown) did not reveal staining for CD73. These data indicate that CD73 is also surface expressed in the human intestine and that like many other surface proteins in this epithelia, expression is influenced by cell lineage (22) and by relative positioning of cells along both the crypt/surface and proximal-distal axis.

Polarity of CD73 surface expression. To define the polarity of CD73 expression by a quantitative biochemical approach, selective cell surface biotinylation was performed (16) with previously described modifications $(14,15)$. Intact circumferential intercellular tight junctions confer on the monolayers high $\left(\sim 1,500 \mathrm{ohm} \mathrm{cm}^{2}\right)$ resistance to passive ion flow, restriction of paracellular diffusion of hydrophilic solutes $(23,24)$ and thus permit selective surface labeling using the biotin probe either apically or basolaterally. After cell lysis, detergent solubilization, specific immunoprecipitation of CD73, and SDS-PAGE, the biotin-conjugated protein is visualized on the nitrocellulose membrane using peroxidase-conjugated strepta- 

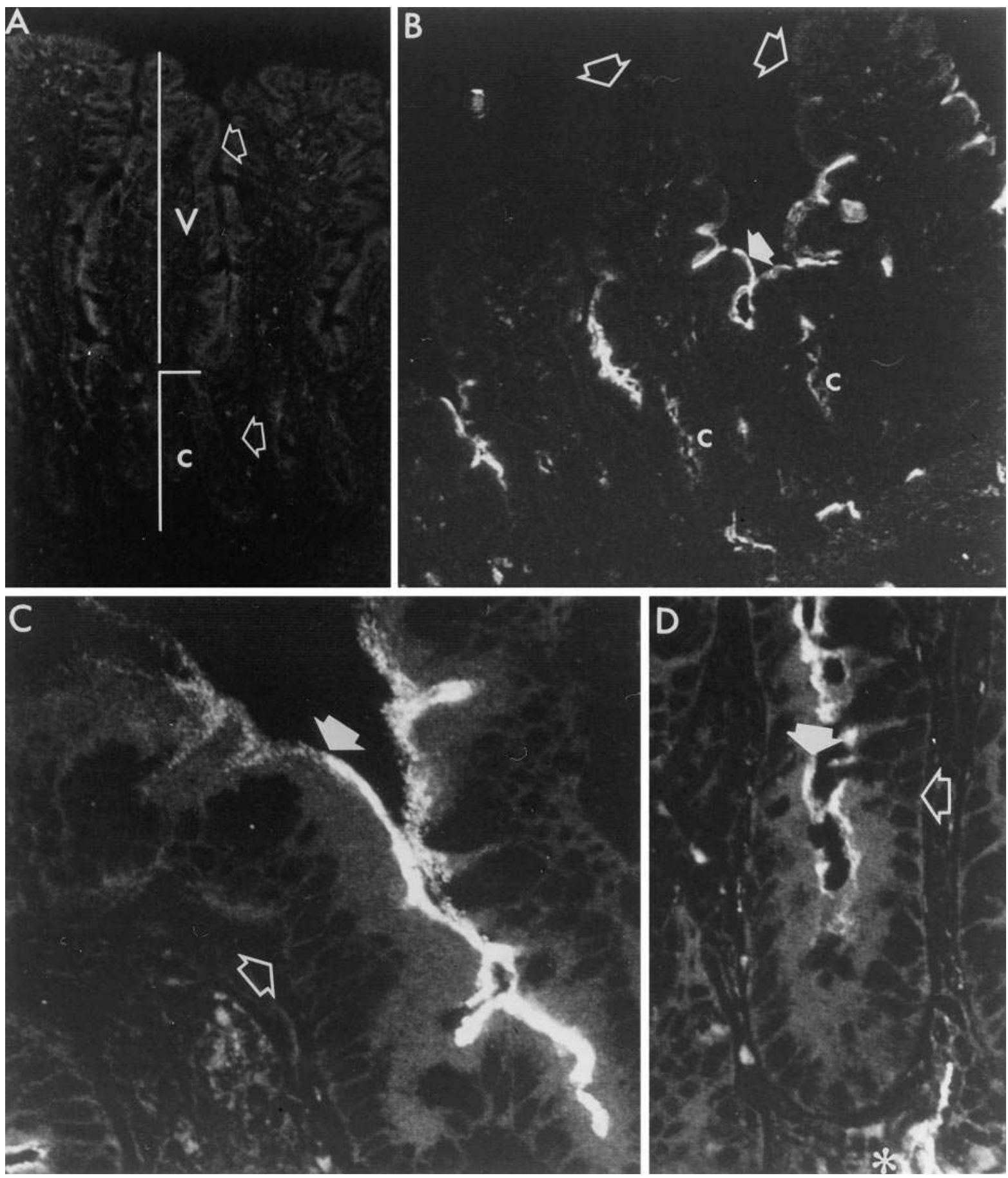

Figure 5. Surface expression of CD73 in human duodenum tissue. Proximal human duodenum (proximal small intestine) tissue was prepared using standard histological techniques. $(A)$ Negative control stained only with secondary antibody (v designates the villus and $\mathrm{c}$ designates the crypt). (B) CD73 staining (open arrows indicate a villus tip which is not stained, the solid arrow points to the lower third of the villus where CD73 was localized, and the c's designate crypts). (C) A higher magnification of the lower third of the villus, with the solid arrow indicating an abrupt transition of CD73 expression on the lumenal side; the open arrow points to the serosal side of the epithelium. $(D)$ A higher magnification of the crypt is shown here, with the solid arrow pointing to the lumenal side and the open arrow indicating the serosal side of the epithelium. The star indicates endothelial cells of the microvasculature.

vidin. As shown in Fig. 7, CD73 is heavily surface expressed by T84 cells and selective biotinylation of apical or basolateral membranes indicates that expression occurs in a preferential, but not strictly polarized, apical manner (exhibiting an apicalto-basolateral ratio of $6.7 \pm 0.8$ (relative units from densitomet- ric scan), mean \pm SE, $n=7$ ). We further examined another GPI-anchored protein, DAF, in our cell line. DAF is a glycosylated GPI-anchored protein $(\sim 65 \mathrm{kD})$ that protects cells from complement-mediated damage by inhibiting the formation and accelerating the decay of $\mathrm{C} 3 / \mathrm{C} 5$ convertase (25). It exhib- 

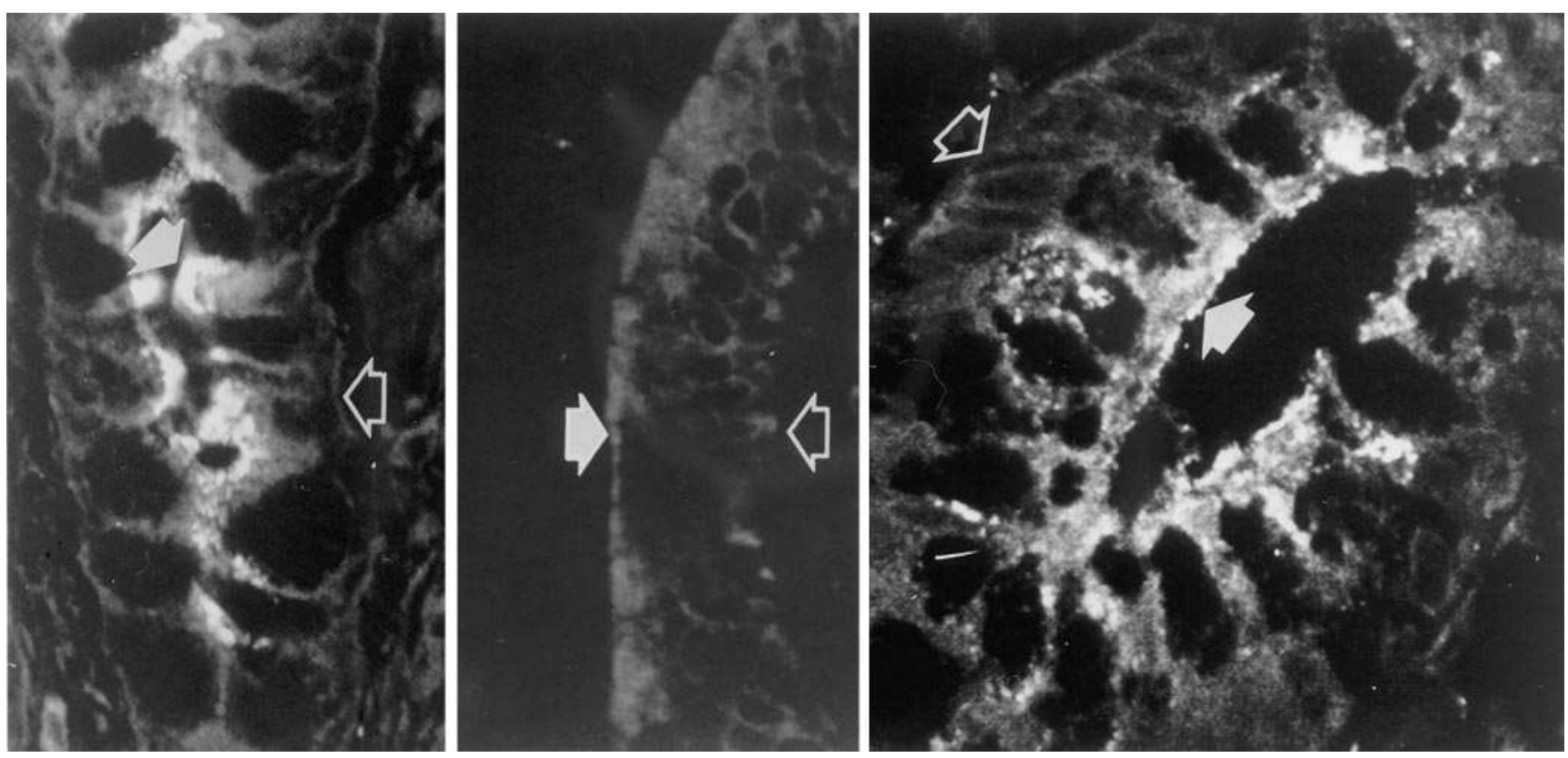

Figure 6. Surface expression in human intestinal cells. Ileum crypt cells are shown in the left panel. The middle panel represents the ileum villus absorptive cells, with a photograph of the crypt of the ascending colon shown in the right panel. Solid arrows designate CD73 staining of the lumenal surfaces, and open arrows indicate negative staining.

ited a broad band centered approximately around a molecular mass of $80 \mathrm{kD}(19,25)$, with an $\sim 2$.4-fold greater expression apically (Fig. 8 B). This demonstrates that two GPI-anchored proteins are apically concentrated in T84 cells.
To test whether CD73 expressed by intestinal epithelia is a GPI-linked protein, we incubated the surface biotinylated cells with PI-PLC before membrane solubilization/immunoprecipitation. As shown in Fig. 7, apically biotinylated monolayers ex-

\section{A CD73 retained}

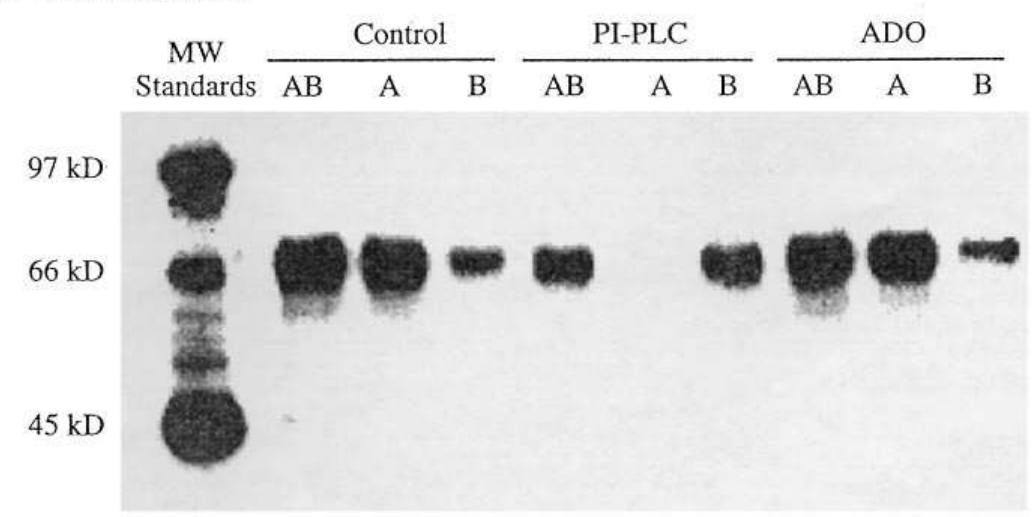

B CD73 Released

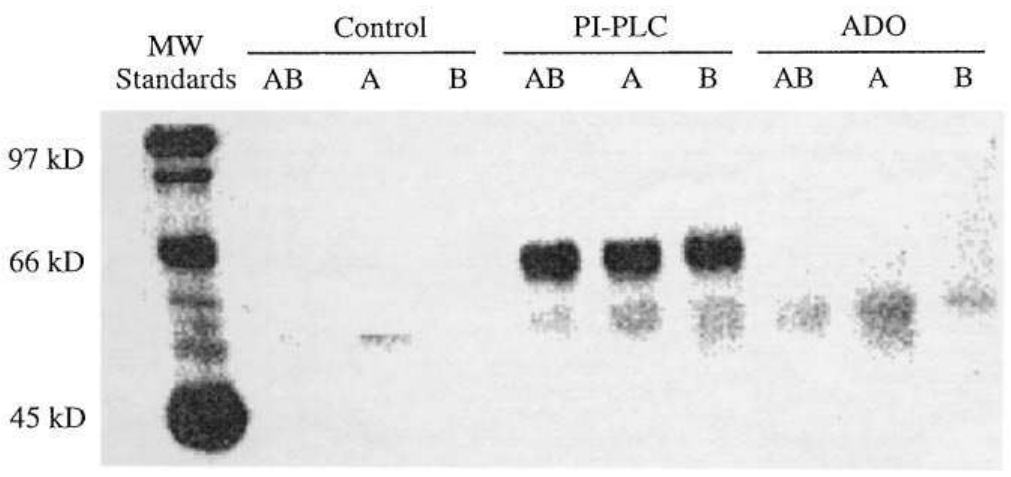

Figure 7. Localization of CD73 using selective cell surface biotinylation, and its release by PI-PLC or stimulation. Cells biotinylated apically $(A)$, basolaterally $(B)$, or both $(A B)$ were solubilized in $1 \%$ NOG, immunoprecipitated, and SDS-PAGE was performed. Control cells reveal that T84 cells express sixfold greater CD73 apically than basolaterally. Biotinylated cells were subsequently treated with phosphatidyl inositol-specific phospholipase C (PI-PLC) for $1 \mathrm{~h}$, thereby releasing all the CD73 on the apical surface. Basolateral CD73 was only released when EGTA was used to open tight junctions, allowing PI-PLC access to the basolateral membrane (not shown). Cells stimulated after biotinylation with adenosine (ADO) or 5'-AMP (not shown) for $1 \mathrm{~h}$ did not shed CD73, but exhibited the same level of biotinylated CD73 signal as untreated control cells. The bottom blot shows the matching supernatants harvested from the monolayers before membrane solubilization, indicating released 5 '-nucleotidase. Biotinylated broad range molecular mass standards shown (MW) were: phosphorylase b (97 kD), BSA (66 kD), and ovalbumin $(45 \mathrm{kD})$. Data are representative of at least five experiments. 


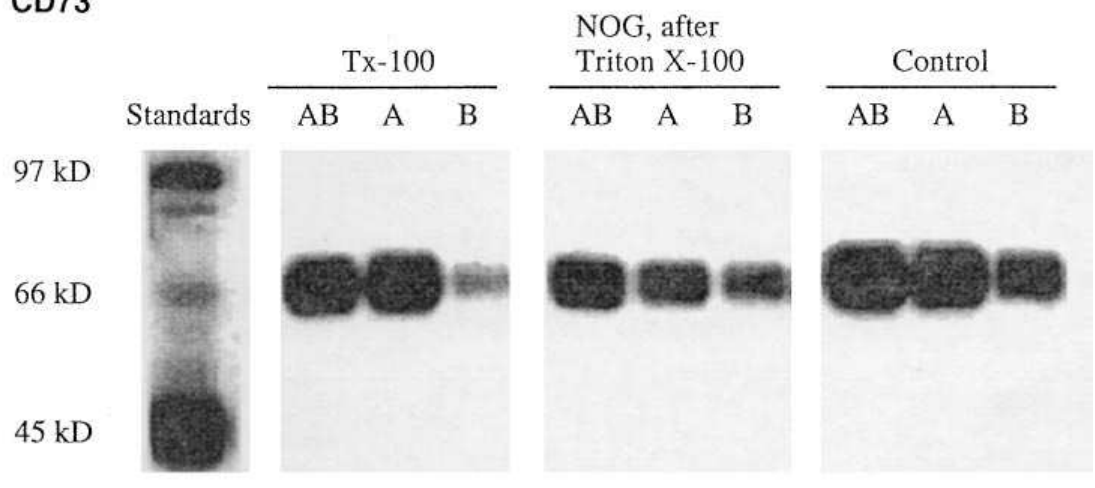

B DAF

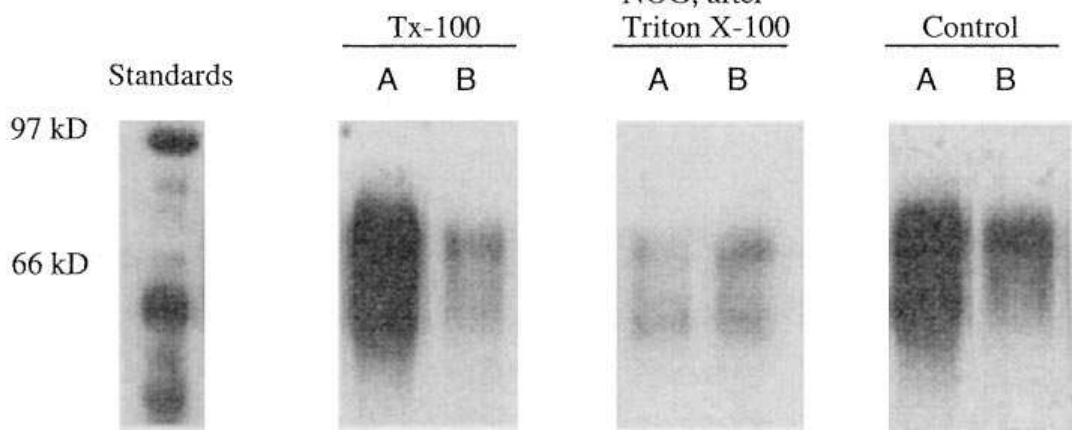

Figure 8. CD73 resistance to TX-100 solubilization. The top figure shows samples biotinylated apically $(A)$, basolaterally $(B)$, or both $(A B)$ as in Fig. 7. The excised filters with attached T84 cells were then extracted by tumbling as described in the Methods, first with TX-100, then after washing with TX-100 extract buffer they were subsequently extracted with $1 \%$ NOG-TX-100 extract buffer to recover any remaining unsolubilized protein (NOG after TX-100). Total CD73 recovered from biotinylated cells using a TX-100 + NOG lysis buffer is shown as Control. All samples were immunoprecipitated and SDS-PAGE performed as in Fig. 7. The proportion of TX-100-soluble CD73 to its NOG extracted, TX-100-insoluble fraction is greater for apically distributed CD73 than for the basolaterally localized protein. The bottom figure shows similar results for DAF, although the basolaterally labeled DAF was extracted more efficiently by TX-100 (compared to the DAF retained by the filters and recovered by NOG extraction), unlike CD73. Data for both figures are representative of at least five experiments. Biotinylated molecular mass standards are listed in Fig. 7. posed to apical PI-PLC lost the CD73 signal (Fig. 7). Biotinylated CD73 could be recovered from the apical supernatant under this condition (Fig. $7 \mathrm{~B}$ ), confirming the GPI linkage of apical CD73 and indicating that PI-PLC treatment had not degraded the protein or the biotin signal. In contrast, we initially found that basolateral CD73 was not released when PI-PLC was applied to the basolateral reservoir (Fig. 7). This result could indicate that basolateral CD73 is not GPI-linked, or alternatively indicate that PI-PLC applied to the basolateral reservoir does not cross the subepithelial matrix and thus is restricted from interacting with basolateral membrane proteins. To resolve this we used conditions (exposure to $2 \mathrm{mM}$ EGTA in $\mathrm{Ca}^{2+}$-free HBSS for $4 \mathrm{~min}$ ) that we have previously shown to be effective in disrupting the tight junction permeability barrier while preserving the phenotype of the polarized columnar monolayer (26) and thus permitting apical access to basolateral domains (27). These latter studies (not shown) revealed that all detectable CD73 is removed from apically plus basolaterally biotinylated cells when PI-PLC treatment is performed after opening intercellular tight junctions. Thus both apical and basolateral pools of CD73 are GPI-linked and PI-PLC does not have access to basolateral compartments unless administered in the apical reservoir to monolayers with discontinuous tight junctions.

We then tested whether the natural ligand of the neutrophil-epithelial paracrine signaling cascade (5'AMP) could regulate surface expression of CD73 via activation of an endogenous phospholipase action. Thus apically biotinylated monolayers were exposed to saturating concentrations $(10 \mu \mathrm{M}$ elicits a maximal Isc response) of 5'-AMP or adenosine and, 30 min after attainment of maximal secretory responses (assessed by measuring short circuit currents at 10 min as in Figs. 1 and 2), surface expression was examined. Such stimulation (shown for adenosine in Fig. 7, same result for 5'-AMP, not shown) did not detectably alter the surface expression of CD73, nor did it increase the release of biotinylated CD73 into the supernatant, demonstrating that CD73 is not significantly released by stimulation with natural agonists/substrates. Thus, the adenosine receptor does not appear to activate any endogenous phospholipase. As another potential means of physiological regulation of $\mathrm{CD} 73$, we used conditions known to induce down-regulation of the T84 response to adenosine to determine if the converting ecto-enzyme and adenosine receptor surface expression were regulated in synchronous or asynchronous fashion. Overnight exposure of monolayers to the nonmetabolizable adenosine analogue $N$-ethylcarboxamidoadenosine (NECA [28]) down-regulated adenosine receptor signal transduction while not influencing other agonist mediated $\mathrm{Cl}^{-}$ secretory pathways that signal through the same second messenger/kinase cascade (Isc responses to $10 \mu \mathrm{M}$ of adenosine applied apically were $3.1 \pm 1.2 \mu \mathrm{A} / \mathrm{cm}^{2}$ vs. $41 \pm 6 \mu \mathrm{A} / \mathrm{cm}^{2}$ for NECA preexposed and control monolayers, respectively; the $\mathrm{Cl}^{-}$secretory responses to $100 \mu \mathrm{M}$ of the cAMP-mediated agonist forskolin for the same conditions were $63 \pm 12 \mu \mathrm{A} / \mathrm{cm}^{2}$ vs. $63 \pm 5 \mu \mathrm{A} / \mathrm{cm}^{2}$, respectively; mean $\left.\pm \mathrm{SE}, n=4\right)$. These data confirm that long-term NECA exposure selectively down-regulates elements of the adenosine-stimulated secretory pathway but that CD73, the ectoenzyme in this pathway, is independently regulated from the receptor.

Comparison of CD73 to another GPI-linked epithelial protein and analysis of TX-100/NOG release. GPI-anchored proteins may be sequestered in distinctive microdomains, thought 

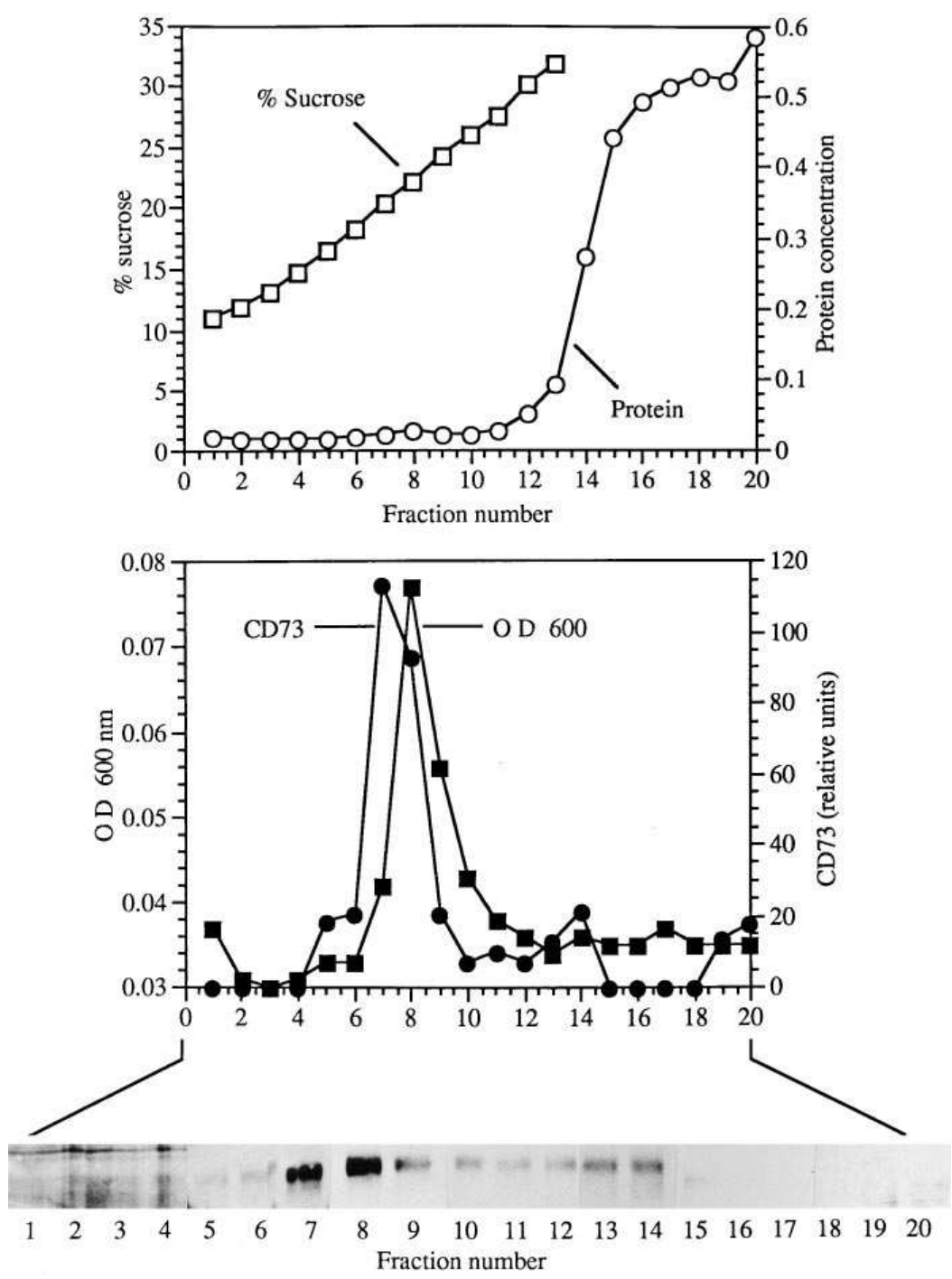

Figure 9. Sucrose density gradient analysis of CD73 from T84 cell lysates. Confluent T84 cell monolayers grown on $45-\mathrm{cm}^{2}$ filters were lysed in cold $1 \%$ TX-100 lysis buffer, mixed $1: 1$ with $60 \%$ sucrose and a $5-30 \%$ sucrose gradient formed over them, as described in Methods. After centrifugation to equilibrium, $0.5-\mathrm{ml}$ fractions were collected from the top, and the fraction samples were analyzed for protein concentration (top graph, $\bigcirc$ ), percent sucrose using a 0-32\% refractometer (top graph, $\square$ ), and light scattering at OD $600 \mathrm{~nm}$ (bottom graph, $\mathbf{\square}$ ), graphed against fraction number. SDS-PAGE was then performed on the fraction samples using a $10 \%$ acrylamide gel and the resulting nitrocellulose blots examined for CD73 by Western blot ( $50 \mu \mathrm{l}$ per sample), shown in the bar at the bottom (each lane is lined up with the fraction numbers in the graphs above). The data were scanned and bands analyzed by densitometry using NIH Image (bottom graph, $\bullet$ ). This graph represents at least eight experiments, and demonstrates that CD73 is completely recovered in the sucrose gradient only in a band of low density, a region exhibiting low protein concentration and high light scatter. to be important in signal transduction and characterized in part by insolubility to $1 \% \mathrm{TX}-100$ at $4^{\circ} \mathrm{C}$ but solubility to $1 \%$ NOG at $4^{\circ} \mathrm{C}$ (29-31). As such, we examined the ability of the detergents TX $-100\left(4^{\circ} \mathrm{C}\right)$ and NOG to extract this protein from the cell membrane. Monolayers were sequentially extracted with these two detergents (Fig. 8) by removing the monolayers intact on their filter supports and first tumbling them in TX100 lysis buffer at $4^{\circ} \mathrm{C}$ for $30 \mathrm{~min}$. These samples represent the TX-100-extracted fractions. The monolayers were then washed repeatedly with TX-100 before extracting the monolayers using NOG-lysis buffer at $4^{\circ} \mathrm{C}$ (NOG, after TX-100). These samples represent the TX-100-resistant fractions. Control monolayers were extracted at $4^{\circ} \mathrm{C}$ using a lysis buffer containing both TX-100 and NOG. As shown in Fig. 8, although a significant fraction of apically biotinylated CD73 was retained in the monolayer after Triton X-100 extraction (i.e., TX-100 resistant), $>50 \%$ of apical CD73 was released by TX-100 at $4^{\circ} \mathrm{C}$ (i.e., TX-100 extracted). The fractional component of apical CD73 recovered in the TX-100-resistant fraction was $38 \% \pm 2 \%$ of total apical CD73 recovered by TX-100 and NOG extractions. In contrast, the fractional component of basolateral CD73 recovered in the TX-100 resistant fraction was higher $(60 \% \pm 11 \%)$. Thus, the apparent TX-100 solubility of CD73 depends in part on the polarity of expression. The reason(s) for the differential effect of TX-100 on apical and basolateral CD73 remains unknown but are likely to reflect different structural features of these two membrane domains. As will be shown below, the CD73 fraction released by TX-100 (i.e., TX-100 extracted) did not actually represent solubility in detergent; rather an intact, nonsolubilized membrane microdomain is lifted out of the plasma membrane and released from the monolayer.

To compare relative surface expression and profiles of detergent-elicited release of CD73 with another epithelial expressed protein known to be GPI-linked, similar analyses of DAF were performed. DAF was, like CD73, found to be dominantly, though not exclusively apically polarized in T84 cells (Fig. 8). Also like CD73, the majority of apical DAF was released by TX-100, exhibiting a high ratio of extraction $(87 \pm 18 \%)$. The basolateral pool of DAF was evenly split between TX-100-extracted and TX-100-resist fractions (54 $\pm 26 \%$ for TX-100-solubilized DAF).

It is thought that GPI-anchored proteins may shift localization to membrane microdomains characterized by distinctive 

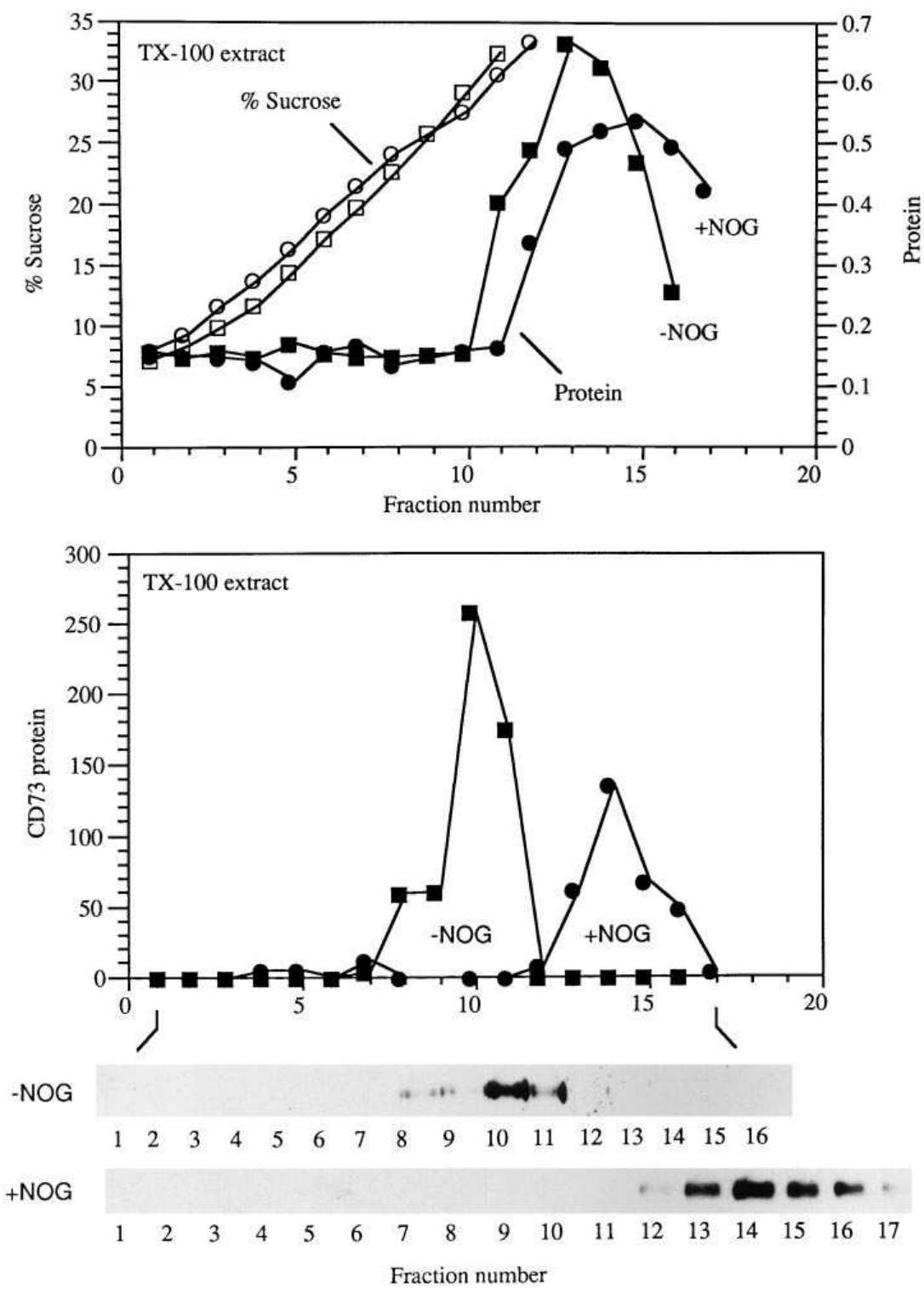

Figure 10. Sucrose density gradient analysis of differentially extracted CD73 from T84 cell lysates. Confluent T84 cell monolayers grown on $45-\mathrm{cm}^{2}$ filters were used to prepare samples for use in sucrose gradients, as described in Methods. Cells were scraped, then solubilized by $1 \%$ TX-100 and dounced $6 \times$ and brought to $4 \mathrm{ml}$ with additional TX-100 lysis buffer. This sample was divided into two tubes, with one tube being kept on ice while the other received $2 \%$ NOG and was warmed to $37^{\circ} \mathrm{C}$ for $15 \mathrm{~min}$ to solubilize and disrupt any membrane fragments ("rafts") in the sample. Both tubes were mixed with $60 \%$ sucrose $1: 1$, run on sucrose gradients and the fractionated samples examined by Western blot for CD73 as performed in Fig. 9. The top graph shows the percent sucrose measurements (open symbols) and relative protein (closed symbols) of each fraction (NOG-treated samples, circle symbols; TX-100 only, square symbols). Both gradients had identical, continuous percent sucrose gradients and similar protein profiles. The OD 600 (not shown) indicated a peak only in the TX-100-only sample around fraction 10 as observed in Fig. 9; no OD peak was observed in the NOG-treated sample. The bottom graph shows the TX-100 lysate fractions (square) compared to the NOG-treated fractions (circle), which demonstrate that CD73 was recovered in a low-density membrane fragment that could be disrupted by NOG, resulting in CD73 localization in the high density region of the sucrose gradient. The two Western blots shown on the bottom display the TX-100 (top) and NOG-treated (bottom) samples, with the lanes lined up with the appropriate fraction numbers of the graphs above them. This presents one experiment of two. detergent solubility as a function of either binding to the agonist recognized by the GPI-anchored protein, or upon crosslinking of the GPI-anchored protein $(32,33)$. We therefore performed experiments by biotinylating monolayers, then exposing them to the CD73 ligand (5'-AMP) or sequentially to anti-CD73 (1E9) and secondary (goat anti-mouse) antibodies to cross-link CD73 as previously described (34). Neither stimulating with 5'AMP nor cross-linking CD73 with antibody altered the proportion of apical CD73 resistant to release by TX-100 (not shown).

Density characteristics of plasma membrane microdomains expressing CD73. To show that the triton-extracted fraction of CD73 was associated with membrane fragments lifted from the cell and not truly solubilized by TX-100, we examined the localization of CD73 in triton extracts floated in a sucrose gradient. If CD73 is found in a low density fraction of a sucrose gradient, then that would suggest that CD73 is localized to DIGs-like membrane domains in T84 cells $(4,30,31,35,36)$. We thus used the sucrose gradient technique, with immuno- blot analyses of the resulting sucrose density fractions, to better define the microdomain in which surface CD73 was localized. As shown in Fig. 9, CD73 from 1\% TX-100-extracted T84 cells was found to localize completely to a light density fraction containing $22.3 \pm 3.8 \%$ sucrose $\left(1.09 \pm 0.02 \mathrm{~g} / \mathrm{cm}^{3}\right.$, mean $\pm \mathrm{SE}, n=$ 10). This peak was coincident with membrane-containing fractions (as defined by light scatter at OD 600), and occurred at a density well separated from the bulk of solubilized proteins, which were observed at the bottom of the gradient.

The above findings (TX-100 resistance and localization to low-density sucrose gradient fractions) indicate that CD73 may be localized to detergent insoluble glycolipid-enriched plasma membrane microdomains. However, DIGs are characteristically not solubilized by TX-100 at $4^{\circ} \mathrm{C}$, and as demonstrated in Fig. 8, we had found that the majority of CD73 was released by TX-100 at $4^{\circ} \mathrm{C}$. One possible explanation for these findings was that disruption of the apical membrane domain by TX-100 allowed release of intact, but TX-100-insoluble, lipid rafts into the supernatant. To test this, we determined 


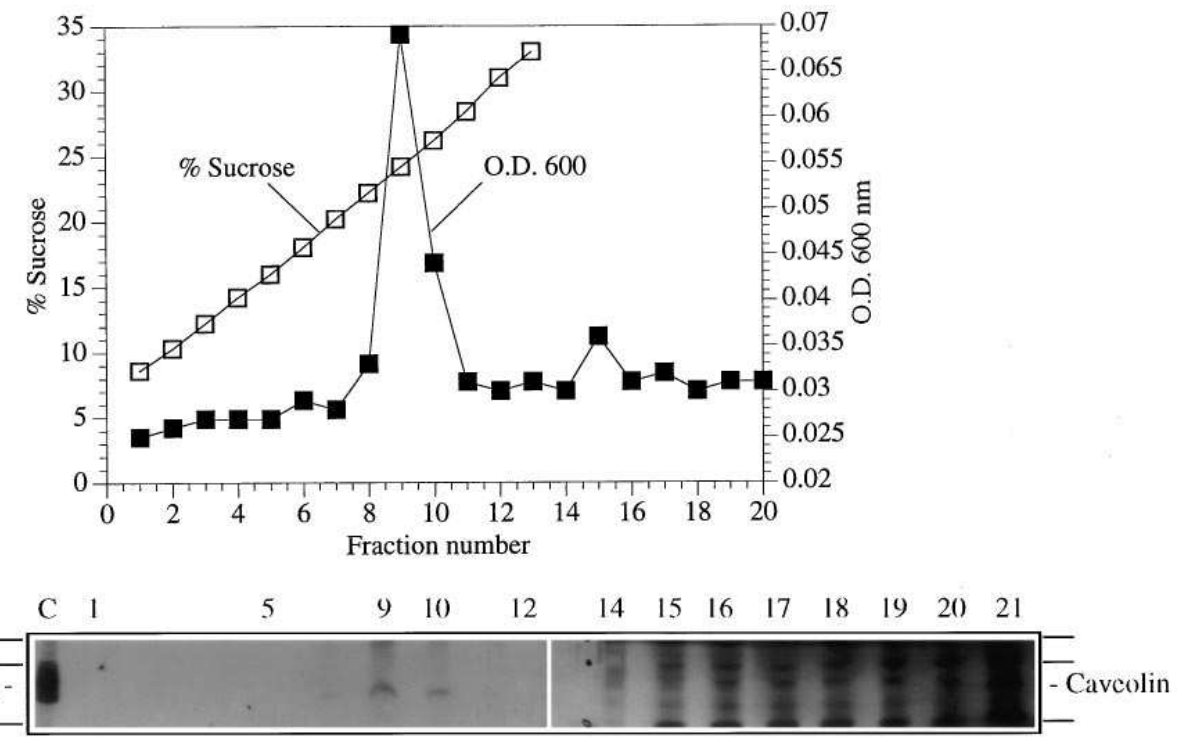

Figure 11. Sucrose density gradient analysis of caveolin from T84 cell lysates. Fraction samples prepared as described in Fig. 10 were analyzed for protein concentration, percent sucrose using a $0-32 \%$ refractometer $(\square)$, and light scattering at OD $600 \mathrm{~nm}(\boldsymbol{\square})$, graphed against fraction number. SDS-PAGE and Western blot analysis of caveolin is shown in the bar at the bottom. This representative graph demonstrates that T84 cells express low levels of caveolin, and the caveolin is recovered in the sucrose gradient only in a band of low density identical to that observed for CD73.

whether the CD73 released by TX-100 was in fact associated with a low density membrane. If so, we would predict that TX100 extracted CD73 would be solubilized from such light membranes with $1 \%$ NOG. To investigate the NOG solubilization of TX-100 extracted CD73, T84 cells were initially scraped from the membrane support, then solubilized in TX-100 and dounced. This preparation was then divided into two test tubes, one of which was kept cold. NOG was added to the other test tube and the extract was warmed to $37^{\circ} \mathrm{C}$ for $10 \mathrm{~min}$. This treatment should cause any TX-100 resistant membrane fragments to become fully solubilized, resulting in CD73 retention at the bottom of the sucrose gradient. As shown in Fig. 10, CD73 extracted by TX-100 was indeed released as a membrane fragment with characteristics of a DIGs-like fraction. In the bottom graph of Fig. 10, CD73 extracted only by $1 \%$ TX100 at $4^{\circ} \mathrm{C}$ was found exclusively in a low density region of the gradient. However, when this extract was further solubilized using NOG, the light fraction defined by absorbance at $600 \mathrm{~nm}$ was lost, and CD73 shifted to higher density fractions where the bulk of solubilized proteins were located (Fig. 10, bottom graph). Furthermore, in experiments where T84 cells were extracted with $1 \% \mathrm{TX}-100$ at $4^{\circ} \mathrm{C}$, then $\mathrm{CD} 73$ was immunoprecipitated and run on SDS-PAGE, multiple protein bands were visualized by both Coomassie blue stain and silver stain (not shown), indicating that other proteins were isolated in the immunoprecipitated membrane fragments.

Some cell types such as lymphocytes contain DIGs-like microdomains without any of the characteristic caveolae morphologic features (37). Since epithelial cells exhibit little or no caveolar-like structures (W.I. Lencer and J.L. Madara, personal observations), but do contain DIGs-like microdomains as shown in the present work, we finally sought to determine whether the membrane fragments isolated in the sucrose gradient contained the caveolar protein caveolin by Western blot. As shown in Fig. 11, T84 cells express caveolin, and it is found in the low density region of the sucrose gradient. Thus, CD73 fractionates with membranes that display the major biophysical characteristics of DIG-rich membrane domains that contain caveolin.

\section{Discussion}

We demonstrate that intestinal epithelial cells express an ectonucleotidase activity critical to processing the paracrine signal 5 -AMP to the extracellular effector, adenosine. The nucleotidase activity is the result of the expression of the ecto- 5 -nucleotidase CD73. CD73 surface expression is not acutely altered by interaction with its substrate, $5^{\prime}$-AMP, nor by activation of downstream signals triggered by release of its product, adenosine. CD73 surface expression is also distinctly regulated from the $\mathrm{A}_{2 \mathrm{~b}}$-adenosine receptor that is responsible for the adenosine response elicited from intestinal epithelial cells, since long-term stimulation of the receptor down-regulates the Isc response but has no effect upon CD73 surface expression (G. Strohmeier and J. Madara, personal observations). The CD73 ecto-enzyme appears to localize to distinct plasma membrane microdomains that display all the major characteristics of DIGs, including localization of caveolin. Although TX-100 can release a large pool of CD73, particularly from the apical membrane where the bulk of this protein resides, this does not represent true protein solubilization. Rather, as we show here, intact membranes (glycolipid rafts) containing CD73 are released from components of the monolayer (which remains intact on the filter support; Lencer, W.I., unpublished observations).

CD73 is a purine salvage enzyme located on the external surface membrane of a wide range of cell types $(21,38-40)$. CD73 serves a regulatory role in neurotransmitter release (40), functions to control blood flow (39) and may play a role in the immune system response (34). The cDNA has been cloned from human placenta and bovine and rat liver. The protein was shown to be composed of 574-amino acid residues, yielding a core protein of $63 \mathrm{kD}(8,41)$. In these tissues, CD73 is a dimer $(41,42)$ that is $\mathrm{N}$-glycosylated with a final monomer apparent molecular mass of $73 \mathrm{kD}$, and anchored to the plasma membrane by a glycosylphosphotidylinositol-linkage (GPIanchor) (41, 43). As we now show in intestinal epithelia, CD73 is released from the membrane by digestion with exogenously added PI-PLC (8) and, in principal may be physiologically 
shed in response to agents that activate endogenous phospholipases. However, as we show here, endogenous phospholipase activation resulting in release of CD73 from the plasma membrane does not appear to occur in response to substrate recognition or adenosine-based signal transduction in T84 cells.

Activity of intestinal epithelial CD73. Our initial examination of ecto-5'-nucleotidase activity used an inhibitor of the ecto-5'-nucleotidase CD73, AOPCP. In the presence of AOPCP, the Isc elicited by $5^{\prime}$-AMP or PMN-conditioned buffer (for which 5'-AMP constitutes the majority of the bioactivity observed) were greatly inhibited. We show that conversion of $5^{\prime}$-AMP to adenosine in the bulk fluid occurs most efficiently when $5^{\prime}$-AMP is placed apically, with substantially less conversion observed in the bulk fluid when $5^{\prime}$-AMP is placed basolaterally. This difference may be explained by the difference in volumes of the reservoirs. The basolateral reservoir contains $1 \mathrm{ml}$, while the apical reservoir contains $0.2 \mathrm{ml}$, and thus there is less mass of $5^{\prime}$-AMP available apically to be converted. In addition and more importantly, this polarity in surface conversion correlates well with the relative apical polarization of CD73, as demonstrated by immunofluorescence and selective cell surface biotinylation. These assays reveal that basolateral CD73 can mediate $5^{\prime}$-AMP-induced signal transduction. For example, AOPCP inhibits the Isc response to basolaterally applied 5'-AMP, shifting the $\mathrm{ED}_{50} 55$-fold. Analyses of the doseresponse characteristics of the basolaterally stimulated $\mathrm{Cl}^{-}$ secretory response indicate that such activation must be a result of stimulation of a basolateral adenosine receptor, as has been previously demonstrated (3), and not due to diffusion of a fraction of basolateral 5'-AMP into the apical reservoir.

CD73 or 5'-ectonucleotidase activity has previously been shown to be expressed in duodenal mucosa (21). Here we show that in natural human intestinal epithelia, CD73 displays a distribution that is regionally distinctive. In the proximal small intestine, intense predominately apical staining occurs in both crypt and lower villus surface epithelia. Staining is less intense, however, in the ileum and here is limited to surface epithelia of intestinal crypts. This latter pattern of cell surface CD73 expression is preserved until the distal colon, where very little if any CD73 staining can be appreciated. It is of interest in this regard to note that this pattern of surface expression of CD73 imperfectly matches the distribution of the intestinal epithelial-type of adenosine receptor $\left(\mathrm{A}_{2 \mathrm{~b}}\right.$ receptor, as assessed by Northern blots $[3,44])$. While message for the $A_{2 b}$ adenosine receptor and protein expression of CD73 coexist in the proximal colon, there is no $\mathrm{A}_{2 \mathrm{~b}}$ AdoR message in the ileum, whereas CD73 is clearly expressed in the crypt at that site. These data raise the possibility that the biology of the mechanism of neutrophil derived $5^{\prime}$-AMP signal transduction may vary by site along the axis of the intestine.

Polarity of CD73 expression. The initial observation that stimulated our studies was the recognition that once PMN had transmigrated across intestinal epithelia, they stimulate electrogenic $\mathrm{Cl}^{-}$secretion from the apical surface by a secretory bioactivity identified as $5^{\prime}-\operatorname{AMP}(2,20)$. Since PMN were found not to be able to convert $5^{\prime}$-AMP to adenosine (2), and since this paracrine signal ultimately acted by activation of intestinal epithelial adenosine receptors (3), it was concluded that the apical membrane of such cells displayed an ecto-nucleotidase activity. We show here the ecto-nucleotidase activity to be CD73, which is known to be anchored to the membrane by a GPI linkage. Since it has been proposed that the GPI linkage functions as an apical targeting signal $(30,45,46)$, it is likely that the targeting of CD73 is critical for this regulated paracrine secretory response.

Examination of CD73 polarity revealed a small but significant pool of basolaterally localized ectonucleotidase. Confocal microscopy, functional (Isc) responses to $5^{\prime}$-AMP that is AOPCP inhibitable, and a selective surface biotinylation assay all conclusively demonstrate this basolateral pool. Without basolaterally expressed CD73, T84 cells could not respond to basolaterally applied 5'-AMP, a response that has been reported previously $(2,3)$. The differences reported here in CD73 conversion of $5^{\prime}$-AMP and the differences in $5^{\prime}$-AMP Isc responses and its inhibition by AOPCP between apical and basolateral membranes are explained by several points. First, the ecto-5'-nucleotidase is a high capacity enzyme and thus it is not surprising that the minor component of basolateral nucleotidase can provide sufficient adenosine in the microenvironment of the $A_{2 b}$ receptor to fully activate the cell. In addition, as discussed above, the basolateral reservoir has a fivefold higher volume, and with the greater $5^{\prime} \mathrm{NT}$ expression apically, it is expected that the bulk conversion of 5'-AMP to adenosine observed in Fig. 3 is much more efficient than that observed basolaterally. Lastly, as we previously demonstrated, the basolateral $\mathrm{ED}_{50}$ responses to 5'-AMP and adenosine are shifted one-log from the apical $\mathrm{ED}_{50}$ curve due to depletion of adenosine from the microenvironment of the basolateral membrane due to action of basolateral membrane adenosine transport activity (3). Thus T84 cells exhibit a basolateral ecto-nucleotidase activity.

The small portion of basolaterally expressed CD73 may be functionally important. As summarized in Plagemann et al. (47), intestinal mucosa are deficient in de novo purine biosynthesis and must import preformed purines. Rapid phosphorylation of imported nucleosides prevents their backflow out of the cell. Thus, these transporters do not transport $5^{\prime}$-AMP but transport adenosine. As discussed above, we have shown (3) that the basolateral adenosine dose response curve in T84 cells is shifted by 1-log to higher doses compared to the apical dose response curve due entirely to basolateral import of adenosine. Thus, the small basolateral pool of CD73 might confer on intestinal epithelial cells an ability to import purine presented as $5^{\prime}$-AMP, and in cases of release of large concentrations of 5'-AMP its basolateral expression would permit activation of the basolateral $\mathrm{A}_{2 \mathrm{~b}}$-adenosine receptors.

DAF, another GPI linked protein, has been shown to enter cells by non-clathrin-coated invaginations of a variety of epithelia (48). Such endocytosis may represent internalization by caveolae or detergent insoluble glycosphingolipid-enriched (DIGs) microdomains, membrane structures that are enriched in proteins attached by GPI-anchors $(30,35,36,49,50)$. For this reason we have explored whether CD73 may localize to membrane microdomains characteristic of caveolae or DIGs.

CD73 localization to a membrane lipid subdomain. GPIanchored proteins can be insoluble to nonionic detergent extraction at $4^{\circ} \mathrm{C}$ (such as TX-100) $(30,31,35)$ due to association with membrane microdomains containing cholesterol and sphingolipids $(4,19,49)$. These insoluble membrane fragments may be isolated by sucrose density centrifugation $(4,30,35)$, and are found only in the low density fraction of an isopycnic gradient $(25 \% \pm 4 \%$ sucrose representing a density of $\left.1.10 \pm 0.02 \mathrm{~g} / \mathrm{cm}^{3}\right)$. No CD73 was found in any of the higher density fractions, representing solubilized protein. Thus, CD73 
fractionates clearly with DIGs. Brown et al. (30) showed that human placental alkaline phosphatase was recovered from isopycnic gradients at the same density as we found CD73. Likewise, Lisanti and co-authors (35) demonstrated that the 15 to $20 \%$ sucrose fractions contained TX-100 insoluble complexes containing $85 \%$ of the cells' caveolin and $55 \%$ of GPIlinked marker proteins, while excluding $98 \%+$ of the plasma membrane protein markers. When our purified membranes in the low density fractions were treated with NOG and re-run, they shifted to higher density fractions, providing further evidence that the fraction of CD73 released by TX-100 at $4^{\circ} \mathrm{C}$ is not truly solubilized but is present in an intact low density membrane domain that is lifted out of the plasma membrane. Immunoprecipitating CD73 from TX-100 extracts and visualizing all proteins by Coomassie and silver stains reveal a number of other proteins in the preparation, consistent with the view that $\mathrm{CD} 73$ is present in lipid rafts that are retained or lifted out of the membrane during TX-100 extraction. Whereas T84 epithelial cells exhibit little or no caveolae-like membrane invaginations (W.I. Lencer and J.L. Madara, personal observations), we find that caveolin is expressed by T84 cells at low levels, and fractionates with CD73 on sucrose gradients. These data suggest that CD73 and caveolin may localize to the same membrane microdomain (presumably DIGs) in vivo.

In summary, model human intestinal epithelia express surface CD73 abundantly on their apical domains and to a lesser extent on the basolateral domain. This pattern of surface expression is observed at many sites along the axis of natural human intestine. Both apically and basolaterally located CD73 can be recovered in membranes that display resistance to TX100 solubilization, and expression of caveolin, suggesting that CD73 may be localized to specialized detergent-insoluble membrane domains. These studies indicate that CD73 plays a key role in 5'-AMP-mediated cross-talk between activated $\mathrm{PMN}$ and intestinal epithelia interactions that result in direct stimulation of electrogenic $\mathrm{Cl}^{-}$secretion, the basis of secretory diarrhea.

\section{Acknowledgments}

We gratefully acknowledge Drs. Charles Parkos, and Lisa D'Andrea for valuable discussions and expert technical assistance.

This work was supported by National Institutes of Health grants DK-35932, DK-47662, DK-42125, DK-48106, AI-18220, and GM39699. Dr. Lencer is the recipient of the Samuel J. Meltzer award for basic research in gastroenterology awarded annually by the American Digestive Health Foundation and the Miles and Shilley Foundation, grant number DK 48106.

\section{References}

1. Yardley, J.H. 1986. Pathology of Idiopathic Inflammatory Bowel Disease and Relevance of Specific Cell Findings: an overview. In Recent Developments in the Therapy of Inflammatory Bowel Disease. J.H. Yardley, editor. Johns Hopkins, Baltimore, MD. 3-9.

2. Madara, J.L., T.W. Patapoff, B. Gillece-Castro, S.P. Colgan, C.A. Parkos, C. Delp, and R.J. Mrsny. 1993. 5'-Adenosine monophosphate is the neutrophilderived paracrine factor that elicits chloride secretion from T84 intestinal epithelial cell monolayers. J. Clin. Invest. 91:2320-2325.

3. Strohmeier, G.R., S.M. Reppert, W.I. Lencer, and J.L. Madara. 1995. The $\mathrm{A}_{2 \mathrm{~b}}$ adenosine receptor mediates cAMP responses to adenosine receptor agonists in human intestinal epithelia. J. Biol. Chem. 270:2387-2394.

4. Parton, R.G., and K. Simons. 1995. Digging into caveolae. Science (Wash. DC). 269:1398-1399.

5. Anderson, R.G. 1993. Caveolae: Where incoming and outgoing messen- gers meet. Proc. Natl Acad. Sci. USA. 90:10909-10913.

6. Burger, R.M., and J.M. Lowenstein. 1975. 5'-nucleotidase from smooth muscle of small intestine and from brain. Inhibition by nucleotides. Biochemistry. 14:2362-2366.

7. Frick, G.P., and J.M. Lowenstein. 1976. Studies of 5'-nucleotidase in the perfused rat heart including measurements of the enzyme in perfused skeletal muscle and liver. J. Biol. Chem. 251:6372-6378

8. Thompson, L.F. 1991. 5'-Nucleotidase- an overview of the last three years. In Purine and Pyrimidine Metabolism in Man. R.A. Harkness, G.B. Elion, and N. Zöllner, editors. Plenum Press, New York. 145-150.

9. Williams, M. 1990. Adenosine and adenosine receptors. In The Receptors. D.B. Bylund, editor. Humana Press, Clifton, NJ. p. 196.

10. Madara, J.L., and K. Dharmsathaphorn. 1985. Occluding junction structure-function relationships in a cultured monolayer. J. Cell. Biol. 101:21242133.

11. Shapiro, M., J. Matthews, G. Hecht, C. Delp, and J.L. Madara. 1991. Stabilization of F-actin prevents cAMP-elicited Cl- secretion in T84 cells. $J$. Clin. Invest. 87:1903-1909.

12. Nash, S., J. Stafford, and J.L. Madara. 1987. Effects of polymorphonuclear leukocyte transmigration on barrier function of cultured intestinal epithelial monolayers. J. Clin. Invest. 80:1104-1113.

13. Parkos, C.A., S.P. Colgan, T.W. Liang, A. Nusrat, A.E. Bacarra, D.K. Carnes, and J.L. Madara. 1996. CD47 mediates post-adhesive events required for neutrophil migration across polarized intestinal epithelia. J. Cell Biol. 132: 437-450.

14. Lencer, W.I., S. Moe, P.A. Rufo, and J.L. Madara. 1995. Transcytosis of cholera toxin subunits across model human intestinal epithelia. Proc. Natl. Acad. Sci. USA. 92:10094-10098.

15. Kaoutzani, P., C.A. Parkos, C. Delp-Archer, and J.L. Madara. 1993. Isolation of plasma membrane fractions from the intestinal epithelial model T84. Am. J. Physiol. 264:C1327-C1335.

16. Gottardi, C.J., L.A. Dunbar, and M.J. Caplan. 1995. Biotinylation and assessment of membrane polarity: caveats and methodological concerns. Am. J. Physiol. 268:F285-F295.

17. Laemmli, U.K. 1970. Cleavage of structural proteins during the assembly of the head of the bacteriophage T4. Nature (Lond.). 227:680-685.

18. Towbin, H., T. Staehelin, and J. Gordon. 1979. Electrophoretic transfer of proteins from polyacrylamide gels to nitrocellulose sheets: procedure and some applications. Proc. Natl. Acad. Sci. USA. 76:4350-4354.

19. Lisanti, M.P., Z. Tang, and M. Sargiacomo. 1993. Caveolin forms a hetero-oligomeric protein complex that interacts with an apical GPI-linked protein: implications for the biogenesis of caveolae. J. Cell Biol. 123:595-604.

20. Madara, J.L., C.A. Parkos, S.P. Colgan, R.J. MacLeod, S. Nash, J. Matthews, C. Delp, and W.S. Lencer. 1992. $\mathrm{Cl}^{-}$secretion in a model intestinal epithelium induced by a neutrophil-derived secretagogue. J. Clin. Invest. 89:19381944.

21. Thomson, L.F., J.M. Ruedi, A. Glass, G. Moldenhauer, P. Moller, M.G. Low, M.R. Klemens, M. Massaia, and A.H. Lucas. 1990. Production and characterization of monoclonal antibodies to the glycosyl phosphatidylinositolanchored lymphocyte differentiation antigen ecto-5'-nucleotidase (CD73). Tissue Antigens. 35:9-19.

22. Cohn, S.M., T.C. Simon, K.A. Roth, E.H. Birkenmeier, and J.I. Gordon. 1992. Use of transgenic mice to map cis-acting elements in the intestinal fatty acid binding protein gene (Fabpi) that control its cell lineage-specific and regional patterns of expression along the duodenal-colonic and crypt-villus axes of the gut epithelium. J. Cell Biol. 119:27-44.

23. Madara, J.L. 1990. Pathobiology of the intestinal epithelial barrier. Am. J. Pathology. 137:1273-1281.

24. Dharmsathaphorn, K., and J.L. Madara. 1990. Established intestinal cell lines as model systems for electrolyte transport studies. Methods Enzymol. 192: 354-389.

25. Coyne, K.E., S.E. Hall, E.S. Thompson, M.A. Arce, T. Kinoshita, T. Fujita, D.J. Anstee, W. Rosse, and D.M. Lublin. 1992. Mapping of epitopes, glycosylation sites, and complement regulatory domains in human decay accelerating factor. J. Immunol. 149:2906-2913.

26. Parkos, C.A., S.P. Colgan, A.E. Bacarra, A. Nusrat, C. Delp-Archer, S. Carlson, D.H.C. Su, and J.L. Madara. 1995. Intestinal epithelia (T84) possess basolateral ligands for CD11b/CD18-mediated neutrophil adherence. Am. $J$. Physiol. 268:C472-C479.

27. Cepek, K.L., C.M. Parker, J.L. Madara, and M.B. Brenner. 1993. Integrin $\alpha^{\mathrm{E}} \beta_{7}$ mediates adhesion of $\mathrm{T}$ lymphocytes to epithelial cells. J. Immunol. 150:3459-3470.

28. Barrett, K.E., P.A. Huott, S.S. Shah, K. Dharmsathaphorn, and S.I. Wasserman. 1989. Differing effects of apical and basolateral adenosine on colonic epithelial cell line T84. Am. J. Physiol. 256:C197-C203.

29. Cerneus, D.P., E. Ueffing, G. Posthuma, G.J. Strous, and A. van der Ende. 1993. Detergent insolubility of alkaline phosphatase during biosynthetic transport and endocytosis. J. Biol. Chem. 268:3150-3155.

30. Brown, D.A., and J.K. Rose. 1992. Sorting of GPI-anchored proteins to glycolipid-enriched membrane subdomains during transport to the apical cell surface. Cell. 68:533-544.

31. Mayor, S., and F.R. Maxfield. 1995. Insolubility and redistribution of 
GPI-anchored proteins at the cell surface after detergent treatment. Mol. Biol. Cell. 6:929-944.

32. Rothberg, K.G., Y. Ying, F. Kolhouse, B.A. Kamen, and R.G.W. Anderson. 1990. The glycophospholipid-linked folate receptor internalizes folate without entering the clathrin-coated pit endocytic pathway. J. Cell Biol. 110:637-649.

33. Parton, R.G., B. Joggerst, and K. Simons. 1994. Regulated internalization of caveolae. J. Cell Biol. 127:1199-1215.

34. Thompson, L.F., J.M. Ruedi, A. Glass, M.G. Low, and A.H. Lucas. 1989. Antibodies to 5'nucleotidase (CD73), a glycosyl-phosphatidylinositolanchored protein, cause human peripheral blood T cells to proliferate. J. Immunol. 143:1815-1821.

35. Lisanti, M.P., P.E. Scherer, J. Vidugiriene, Z. Tang, A. HermanowskiVosatka, Y. Tu, R.F. Cook, and M. Sargiacomo. 1994. Characterization of caveolin-rich membrane domains isolated from an endothelial-rich source: implications for human disease. J. Cell Biol. 126:111-126.

36. Rijnboutt, S., G. Jansen, G. Posthuma, J.B. Hynes, J.H. Schornagel, and G.J. Strous. 1996. Endocytosis of GPI-linked membrane folate receptor- $\alpha$. J. Cell Biol. 132:35-47.

37. Fra, A.M., E. Williamson, K. Simons, and R.G. Parton. 1994. Detergentinsoluble glycolipid microdomains in lymphocytes in the absence of caveolae. $J$. Biol. Chem. 269:30745-30748.

38. Gandhi, R., M. Le Hir, and B. Kaissling. 1990. Immunolocalization of ecto-5'-nucleotidase in the kidney by a monoclonal antibody. Histochemistry. 95:165-174.

39. Headrick, J.P., and R.J. Willis. 1989. 5'-Nucleotidase activity and adenosine formation in stimulated, hypoxic and underperfused rat heart. Biochem. J. 261:541-550.

40. Richardson, P.J., S.J. Brown, E.M. Bailyes, and J.P. Luzio. 1987. Ectoenzymes control adenosine modulation of immunoisolated cholinergic syn- apses. Nature (Lond.). 327:232-234.

41. Misumi, Y., S. Ogata, K. Ohkubo, S. Hirose, and Y. Ikehara. 1990. Primary structure of human placental 5'-nucleotidase and identification of the glycolipid anchor in the mature form. Eur. J. Biochem. 191:563-569.

42. Naito, Y., and J.M. Lowenstein. 1981. 5'-Nucleotidase from rat heart. Biochemistry. 20:5188-5194.

43. Bailyes, E.M., M.A.J. Ferguson, C.A.L.S. Colaco, and J.P. Luzio. 1990. Inositol is a constituent of detergent-solubilized immunoaffinity-purified rat liver 5'-nucleotidase. Biochem. J. 265:907-909.

44. Stehle, J.H., S.A. Rivkees, J.J. Lee, D.R. Weaver, J.D. Deeds, and S.M Reppert. 1992. Molecular cloning and expression of the cDNA for a novel $\mathrm{A}_{2}$ adenosine receptor subtype. Mol. Endocrinol. 6:384-393.

45. Lisanti, M.P., and E. Rodriguez-Boulan. 1990. Glycophospholipid membrane anchoring provides clues to the mechanism of protein sorting in polarized epithelial cells. Trends Biochem. Sci. 15:113-118.

46. Simons, K., and A. Wandinger-Ness. 1990. Polarized sorting in epithelia. Cell. 62:207-210.

47. Plagemann, P.G.W., R.M. Wohlhueter, and C. Woffendin. 1988. Nucleoside and nucleobase transport in animal cells. Biochim. Biophys. Acta. 947: 405-443.

48. Keller, G., M.W. Siegel, and I.W. Caras. 1992. Endocytosis of glycophospholipid-anchored and transmembrane forms of CD4 by different endocytic pathways. EMBO J. 11:863-874.

49. Anderson, R.G.W. 1993. Plasmalemmal caveolae and GPI-anchored membrane proteins. Curr. Opin. Cell Biol. 5:647-652.

50. Schnitzer, J.E., J. Liu, and P. Oh. 1995. Endothelial caveolae have the molecular transport machinery for vesicle budding, docking, and fusion including VAMP, NSF, SNAP, annexins, and GTPases. J. Biol. Chem. 270:1439914404 